\title{
Geophysical Study by Electrical Soundings of the Tartar Aquifer Unit, Boujdour Region, Morocco
}

\section{Mohamed Chibout1, Anasse Benslimane1, Mohamed El Mokhtar',3, Sidi Mokhtar El Kanti2,4, Fatima Zahra Faqihi', Lahcen Gourari1}

${ }^{1}$ Geodynamics Laboratory of Natural Resources (LGRN), Dhar Mahraz Faculty of Science, Sidi Mohamed Ben Abdellah University, Fez, Morocco

${ }^{2}$ Geosciences Laboratory of Natural Resources (LGRN), Hydroinformatics Team, Faculty of Science, Ibn Tofail University, Maamora Campus, Kenitra, Morocco

${ }^{3}$ AFRICA GEO-SERVICES Society, Fez, Morocco

${ }^{4}$ Sakia El Hamra and Oued Eddahab Hydraulic Basin Agency, Laayoune, Morocco

Email: medsaid@yahoo.com

How to cite this paper: Chibout, M., Benslimane, A., El Mokhtar, M., El Kanti, S.M., Faqihi, F.Z. and Gourari, L. (2020) Geophysical Study by Electrical Soundings of the Tartar Aquifer Unit, Boujdour Region, Morocco. International Journal of Geosciences, 11, 58-83.

https://doi.org/10.4236/ijg.2020.113005

Received: August 21, 2019

Accepted: March 3, 2020

Published: March 6, 2020

Copyright (c) 2020 by author(s) and Scientific Research Publishing Inc. This work is licensed under the Creative Commons Attribution International License (CC BY 4.0).

http://creativecommons.org/licenses/by/4.0/

\begin{abstract}
The Tartar aquifer unit, is located at the SSO of the city of Boujdour, at a distance of nearly $86 \mathrm{~km}$, and crossed (in its western part) by the National Road $\mathrm{N} 1$ connecting the towns of Boujdour and Lagouira passing through the vicinity of the city of Dakhla (PK40). It is exploited by rural settlements for domestic use (especially the inhabitants of fishing villages) and livestock watering, only through wells named Khtout Hobia (IRE 126/124) and Hassi Tartar known as Khtout Trayh (IRE 104/124). These wells have been tracked by a piezometric groundwater table and from 2011 to the present day. The interpretation of the electrical soundings in $A B \leq 2000 \mathrm{~m}$ allowed to differentiate the presence of two families of electrical soundings $A$ and $B$, to establish the resistivity maps in $\mathrm{AB}=200,300$ and $400 \mathrm{ihm} \cdot \mathrm{m}$ with qualitative aspects, to draw up the map of the isohypses of the roof of the intermediate Dt1 representing the impermeable floor of the aquifer and to highlight two types of discontinuities; electrical discontinuities corresponding to lateral facies changes (limit of erosion surfaces) separating the families A and B of electrical soundings and those corresponding to syn-sedimentary faults which structured the formations into horsts and grabens. The lithological sections of the existing water points and that of oil well 43-1 allowed the geological identification of the geoelectric layers highlighted by the electrical soundings diagrams. As a result, the sandstone and lumachelic formations constituting the aquifer are of Moghrebian-Pleistocene age represented by the resistant $\mathrm{R}$ (Family A), sometimes grouping, in its basal part, sandstone levels of the Mi-
\end{abstract}


ocene roof (Family B). These formations lie directly on the Miocene sandy marls represented by the intermediate Dt1. For the present work, we will focus only on the transverse geoelectric cross-section TA, with an SW-NE orientation, which characterizes all the longitudinal sections established following the correlation between the different electric sounding diagrams. It highlights the presence of the gravels G1 and G3 separated by the horst H1 where the resistant $\mathrm{R}$ is admitted as aquiferous at the level of the gravels G1 (Khtout Trayh well 104/124) and G3 (well 126/124) and sterile at the level of the horst $\mathrm{H} 1$.

\section{Keywords}

Tartar Aquifer Unit, Vertical Electrical Soundings, Resistivity

\section{Introduction}

The Tartar area and its regions (Boujdour province) have been the subject of some geophysical campaigns, which had as an objective oil exploration where their results led to the realization of drillings such as 43-1 with a total depth of $3972 \mathrm{~m}$ (1961-1962), and 47-1, located south of Tartar, with a depth of $1626 \mathrm{~m}$ (1961).

Since 1975, the Sakia El Hamra Hydraulic Basin Agency, ABHSHOD (former Directorate of the Sahara Hydraulic Region, DRH) and the Directorate of Water Research and Planning, DRPE have carried out other geophysical campaigns, mainly by electric soundings with $A B$ line lengths varying between 10,000 and $20,000 \mathrm{~m}$, sometimes by seismic reflection. This was done with the objective of releasing the water resources of the deep captive aquifers contained in the dolomites of the Upper Cretaceous base and in the sands of the Lower Cretaceous roof constituting a good potential aquifer, without excluding two other geophysical studies carried out by the Sakia El Hamra and Oued Eddahab Hydraulic Basin Agency in the vicinity of the town of Boujdour and in Aftissat, located south of Boujdour. These studies focused on the superficial sandstone and sandstone coastal aquifers of Moghrebo-Pleistocene age of the Quaternary base. This is, in order to supply drinking water, irrigation of agricultural areas and livestock watering respectively to the inhabitants of the town of Boujdour and the fishing village of Aftissat.

In the light of the results of these studies, which concerned surface and deep groundwater, the Sahara Hydraulic Region Directorate (HRD) and subsequently the Sakia El Hamra and Oued Eddahab Hydraulic Basin Agency (ABHSHOD) carried out several boreholes and wells, controlled by logs. The results of these water points were used to identify the geological properties of the geoelectric layers identified by electrical geophysics.

In addition to the geophysical studies mentioned above, there is the current geophysical sounding by boreholes and electric tomography, carried out in the 
Tartar area around the two wells in the Tartar region (126/124 from Khtout Hobia to the SW and 104/124 from Khtout Trayh to the NE). The study area is part of the rural commune of Jraifia, Boujdour province, Laâyoune-Saguia El Hamra region and falls within the Sakia El Hamra and Oued Eddahab Hydraulic Basin (ABHSHOD) action area.

In order to ensure better management of the water resources of the Tartar surface water table, the most heavily used in the region, it is advisable to better define the origin of the supply of this table, to have knowledge of its geometry and extension, with the aim of establishing a more reliable hydrogeological model. To do this, geophysics is asked to map the geological levels that could constitute the potential surface aquifer, known through the two wells of Khtout Hobia and Khtout Trayh, and to have an idea of the appearance of the roof of its impermeable floor. This is in order to better define areas of high hydrogeological potential.

In the following, we will focus only on the results of the qualitative and quantitative interpretation of the 140 short line length electrical soundings $A B \leq 2000$ $\mathrm{m}$ and the reinterpretation of some long line length electrical soundings $\mathrm{AB}=$ $10,000 \mathrm{~m}$.

The maps used for the establishment of the figures are the topographic maps of the Assaq wadi at 1/100,000 and the Spanish geological map No. 10 at $1 / 200,000$.

Access to the field was difficult due to the presence of cliffs located east of the study area, talwegs, wadis and sand dunes.

The topography of the study area is monotonous and is summarized in a series of plateaus slightly inclined towards the Atlantic Ocean (Figure 1) except for the presence of the dune cordon oriented SSO-NNE sometimes separated by slope breaks and by small discontinuous rock cuestas.

The study area is characterized by the presence of many Grarets, of relatively small size, the most important being the one called Graret Swedi, of vast size, located around Khtout Hobia.

The study area is characterized by a coastal Saharan-type climate in warm winter. In the region of Laayoune, the average annual rainfall is $44.55 \mathrm{~mm}$. The average monthly temperature varies between 17.5 (January) and $26.6^{\circ} \mathrm{C}$ (August) [1] [2].

\section{Study Area}

The study area (Hassi Tartar) is located in the central part of the sedimentary basin of Laayoune-Dakhla. This vast marginal sedimentary basin was formed on the northwestern edge of the African craton when the Atlantic Ocean began to open in the Triassic period. It is part of a coastal geological context formed during the geological events responsible for the stratification of the Tarfaya-Boujdour-Dakhla sedimentary basin, it was the regression and transgression of the Atlantic Ocean. It consists of the outcrops of lithological formations from the Tertiary to the Quaternary age described under a simplified nomenclature 


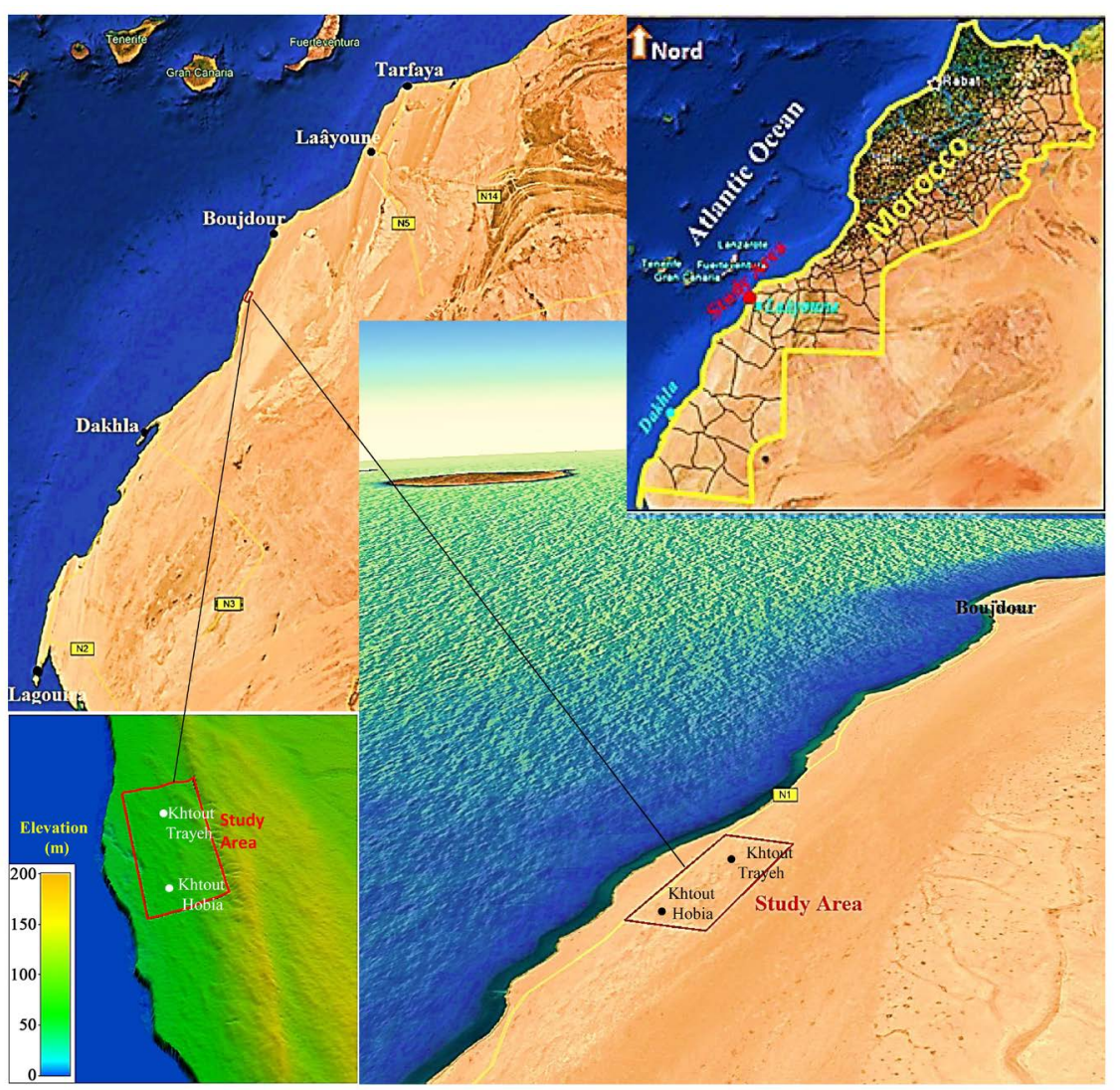

Figure 1. Geographic location of the study area.

“Meso-cenozoic Tarfaya-Laayoune-Boujdour-Dakhla Basin" [3] [4]. Several authors have worked on various aspects of the regional and structural geology of this sedimentary basin [5]-[13] based on data from oil wells and seismic soundings carried out by the Compagnie Générale de Géophysique [14]. These different authors were able to describe the sedimentary basin since the Triassic and recent Quaternary periods by defining the structural geology and litho-stratigraphy of the various geological formations identified by hydraulic and oil drilling. According to the technical note SEGM/n ${ }^{\circ} 107$ (Stratigraphic correlations of drilling in Western Sahara) and the Spanish maps at a scale of 1:200,000 and 1/1,000,000 (Figure 2 and Figure 3), regional geology is characterized by two sedimentary cycles: the Precambrian and Primary (from Precambrian to Carboniferous) and Meso-Cenozoic (from Triassic to Quaternary).

Locally the Tartar region (Figure 3), part of the coastal zone, is covered mainly by tertiary age Quaternary lithological formations that begin at the top with Holocene formations (Quaternary Roof) formed of dunes, beach sands, evaporated silts and carbonated sandstones that rest on Mogrebian-Pleistocene formations (Quaternary base) formed of sandstone and lumachelles (Marine Pliocene). These formations are directly based on Neogene formations known as Ugranat formations (sandstone, lumachelles and carbonate cement microconglomerates) of Miocene age formed which overcome the sandy marl marls. 


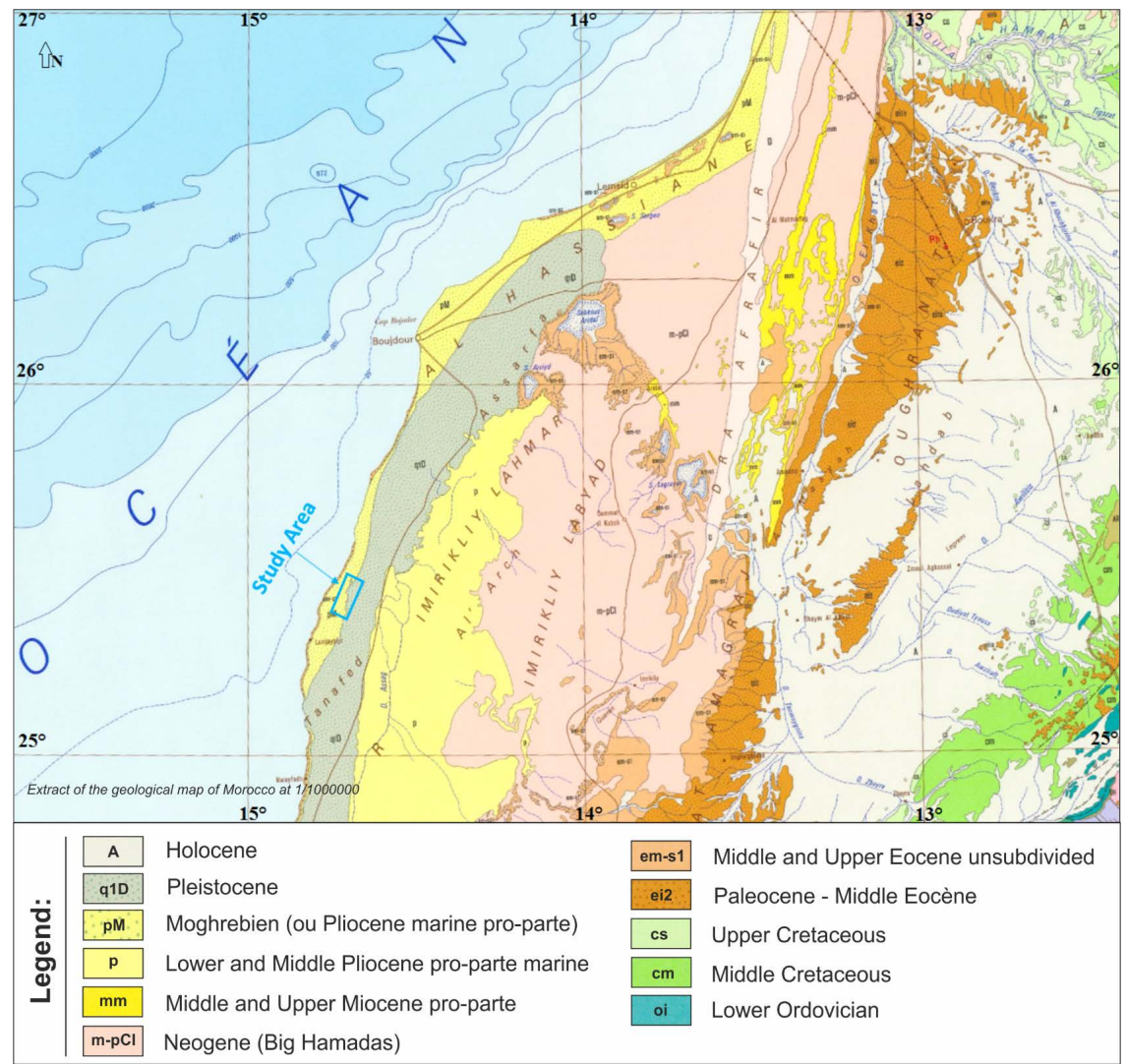

Figure 2. Location plan of the study area and geology.

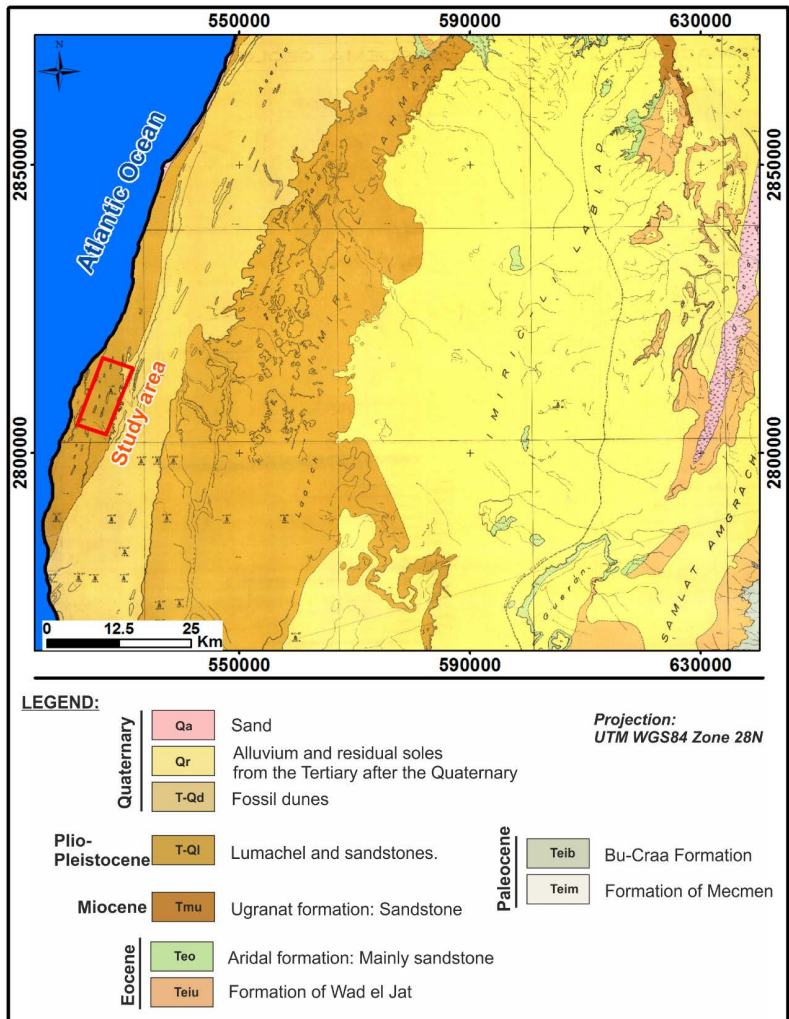

Figure 3. Extract from the geological map of Spanish (Escala-Grafica) at 1/200,000 [15]. 
The whole is based on Eocene formations mainly sands, sandstones, clay banks with the presence of flint.

From a hydrogeological point of view, the main geological formations constituting the Tartar aquifer are Miocene to Moghrebo-Pleistocene in age, consisting of sand, sandstone and lumachelles.

The Tartar surface aquifer unit is located south of the town of Boujdour at a distance of about $76 \mathrm{~km}$ as the crow flies. It is characterized by permeable sandy and sandstone formations, of Plio-Pleistocene age, forming a groundwater reservoir exploited by two wells numbered 126/124 (Khtout Hobia) and 104/124 (Hassi Thrayah) for the supply of drinking water to rural areas and the watering of livestock, the annual volume extracted from this groundwater through these two wells is estimated at about $8000 \mathrm{~m}^{3} /$ year.

The piezometry and water quality of the Tartar groundwater are monitored by these two wells from 2011 to 2019 (Figure 4). The piezometric analysis gives an overview of the dynamic level of the groundwater at the two wells in question, the piezometric fluctuations recorded during the period 2011-2019 oscillate around $20 \mathrm{~m}$ at the level of well 126/124 (Khtout Hobia) (Figure 5) and between 30 and 35 at well 104/120 (Hassi Thrayah) (Figure 6).

The variation in the piezometric level observed at the Khtout Hobia (Puits 126/124) and Khtout Trayh 104/124 wells is mainly linked to abusive groundwater withdrawals for rural drinking water supply, particularly for the inhabitants of neighbouring fishermen's villages and for livestock watering.

The electrical conductivity of the water in the Tartar groundwater varies, in proportion to salinity, between 0.75 and $1.5 \mathrm{mS} / \mathrm{cm}$ at well 126/124 and between 0.53 and $1.75 \mathrm{mS} / \mathrm{cm}$ at well 104/124 (Figure 7 and Figure 8). In addition, the quality of water flowing in sandy and sandstone formations is classified according to Table 1 below as good to average. Figure 6 and Figure 7 below illustrate the evolution of the electrical conductivity of water during the period (February 2011-September 2019).

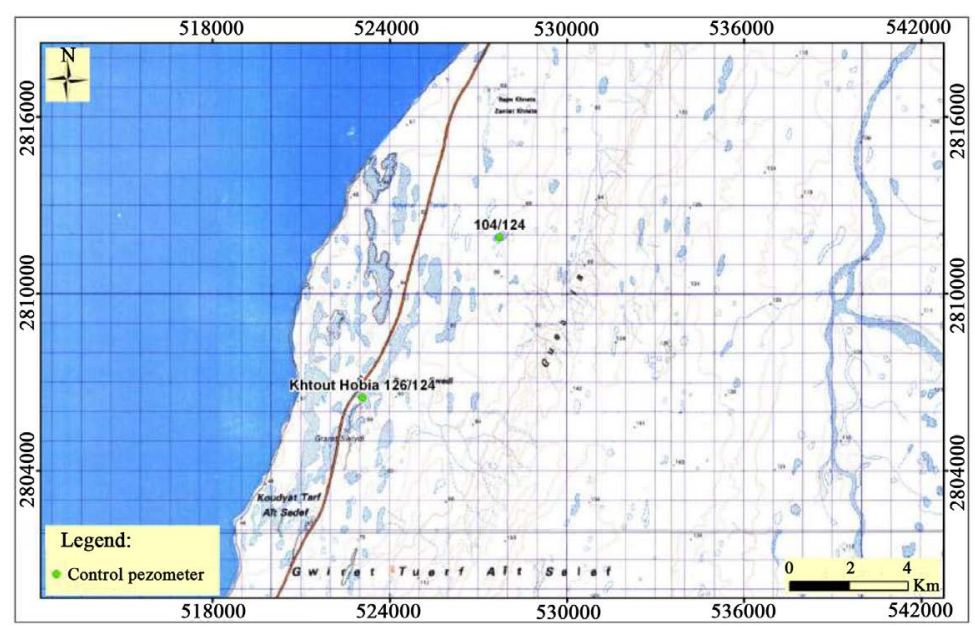

Figure 4. Distribution of piezometric control points and groundwater quality (UTM WGS $8428 \mathrm{~N})$. 


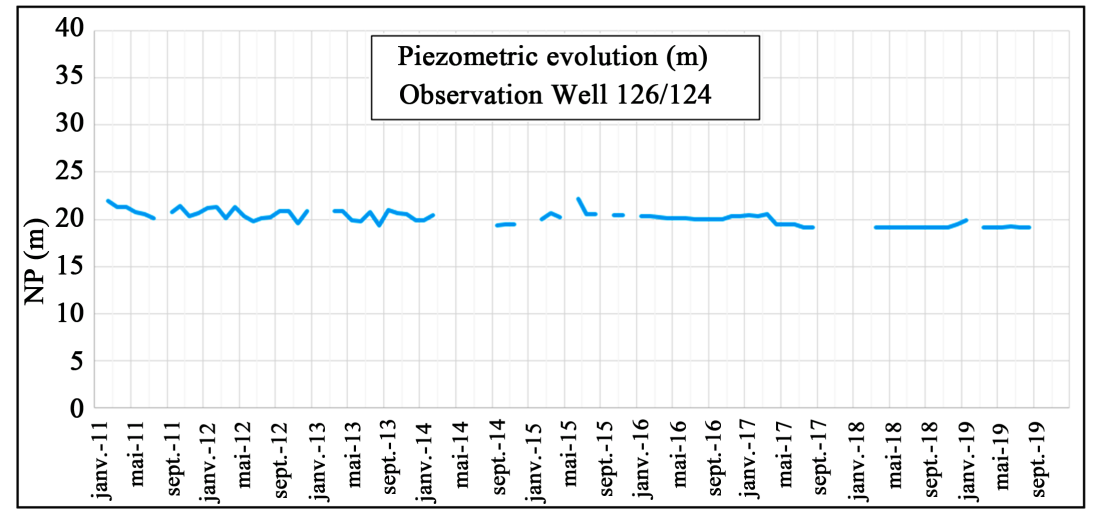

Figure 5. Piezometric evolution at the Khtout Hobia well 126/124.

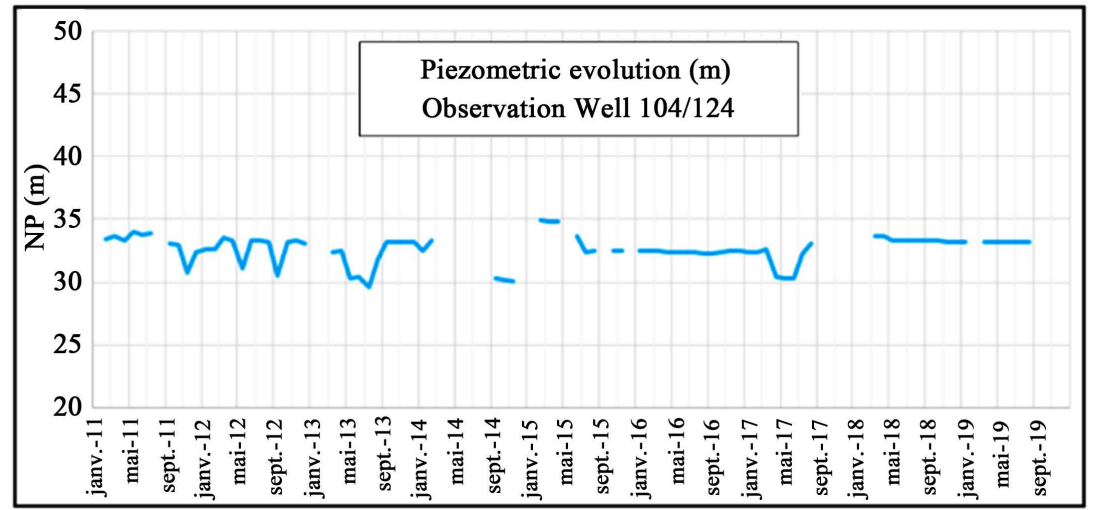

Figure 6. Piezometric evolution at the Khtout Trayah 104/124 well.

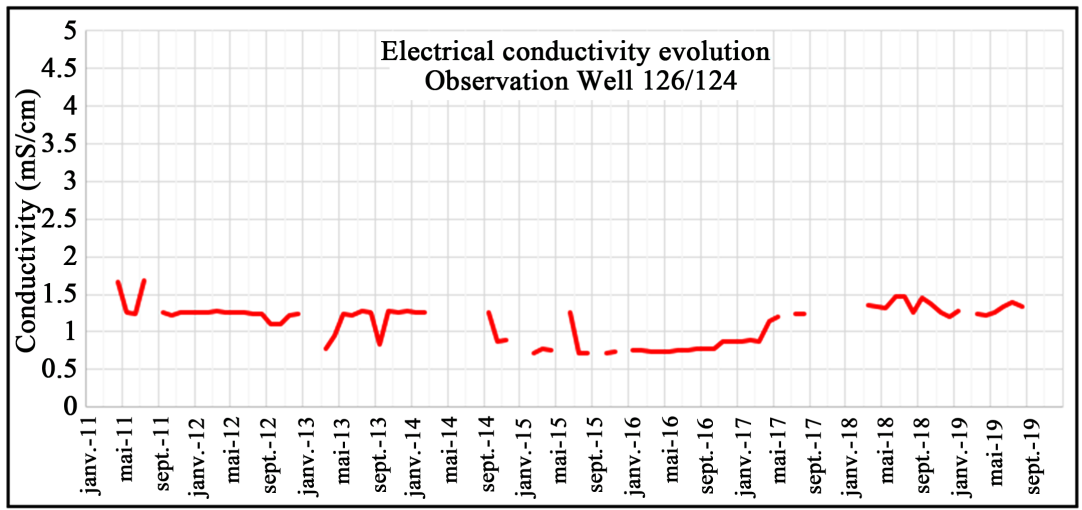

Figure 7. Evolution of water conductivity at the Khtout Hobia well 126/124.

Table 1. Electrical conductivity classes by water quality.

\begin{tabular}{ccc}
\hline Conductivity $(\mathrm{mS} / \mathrm{cm})$ & Quality $(\mathrm{CE})$ & \\
\hline$<0.4$ & Excellent & \\
between 0.4 and 1.3 & Good & $\begin{array}{c}\text { Water from the Tartar } \\
\text { groundwater aquifer is } \\
\text { classified as good to } \\
\text { medium quality }\end{array}$ \\
between 1.3 and 2.7 & Average & \\
between 2.7 and 3 & Wrong & Very Bad \\
\hline
\end{tabular}




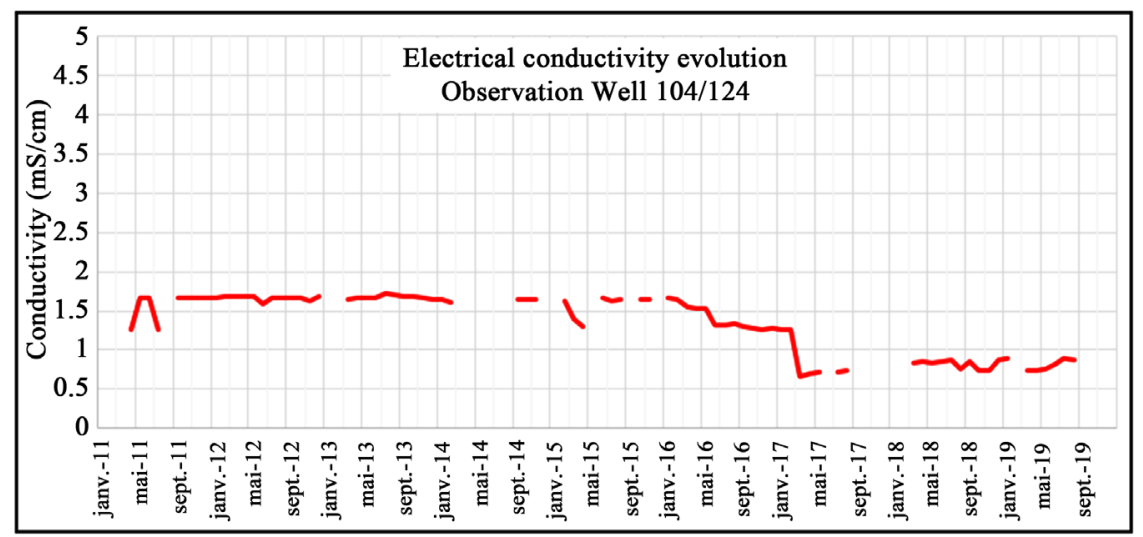

Figure 8. Evolution of water conductivity at the Khtout Trayah 104/124 well.

\section{Methods and Materials}

The geophysical method used in this work is mainly the direct current geoelectric method, essentially vertical electrical soundings (VES). This is the non-destructive subsurface exploration method, is widely used in hydrogeology and engineering geology.

The principle of this geoelectrical method consists in measuring the apparent electrical resistivity, expressed in $\mathrm{ohm} \cdot \mathrm{m}$, of the subsoil layers from the measurement of the difference in potential between two reception electrodes generated by the circulation of the current injected at the surface through two emission electrodes. The resistivity value, according to [16] [17], depends essentially on the water content, water mineralization, clay content and granulometry.

Geoelectrical methods have generally been described in several theses, articles and books. Among the latter are those of [18] [19] [20].

For vertical electrical sounding (VES), the emission (A, B) and reception (M, $\mathrm{N})$ electrodes are distributed in the field according to the Schlumberger device (Figure 9), it is the most suitable device for geoelectrical methods applied to hydrogeology, where the distance between the $\mathrm{M}$ and $\mathrm{N}$ electrodes is significantly smaller than that between the A and B electrodes, in order to minimize the potential deduced from telluric and vagrant currents.

Vertical electrical soundings make it possible to obtain the vertical succession of resistivities in the center of the device at different depths.

It is recalled that the geoelectric method is affected by the principles of equivalence and deletion. All measurements obtained from the electrical soundings, in each selected length, are plotted on bilogarithmic scale diagrams. GeoStudi's SEVplus software will then, after smoothing the curve and inverting the data, obtain a mathematical model giving the depths of the roofs and walls of the different layers plumbing the centre of the electric borehole. This model will be readjusted by the geophysicist in order to have a better estimate of the true resistivity and thickness for each layer while remaining within the limits of equivalence based on the information gathered from the interpretation of the parametric soundings carried out on the boreholes and on the outcrops. 
The hardware used in this work, is GF-Instruments' multichannel ARES II resistivimeter and GEOSTUDI's licensed data transfer and processing software $\left(\mathrm{SEV}^{\text {plus }}\right)$, was used to acquire vertical electrical boreholes, this apparent resistivity meter and processing software, are available from AFRICA GEO-SERVICES.

The situation of the electrical soundings drilled in the study area, wedging boreholes, the two named groundwater wells (Khtout Hobia and Khtout Trayh) of interest to this area and also the geo-electric sections are shown in the following Figure 10.

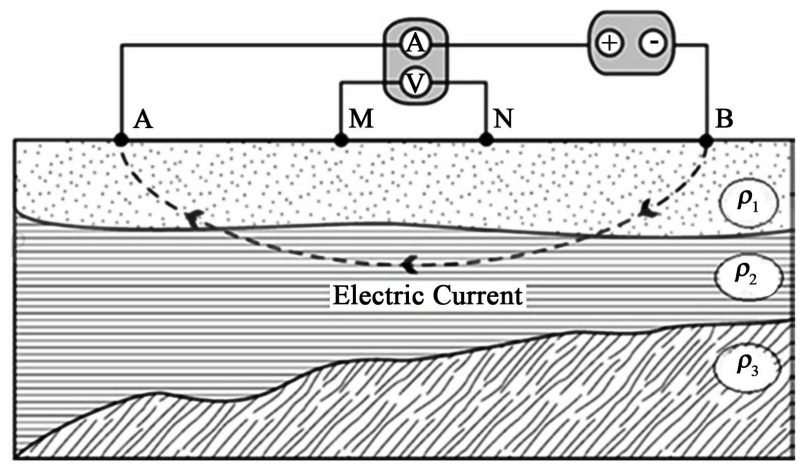

Figure 9. Principle of measuring the apparent resistivity of the subsoil using a device quadrupole in borehole.

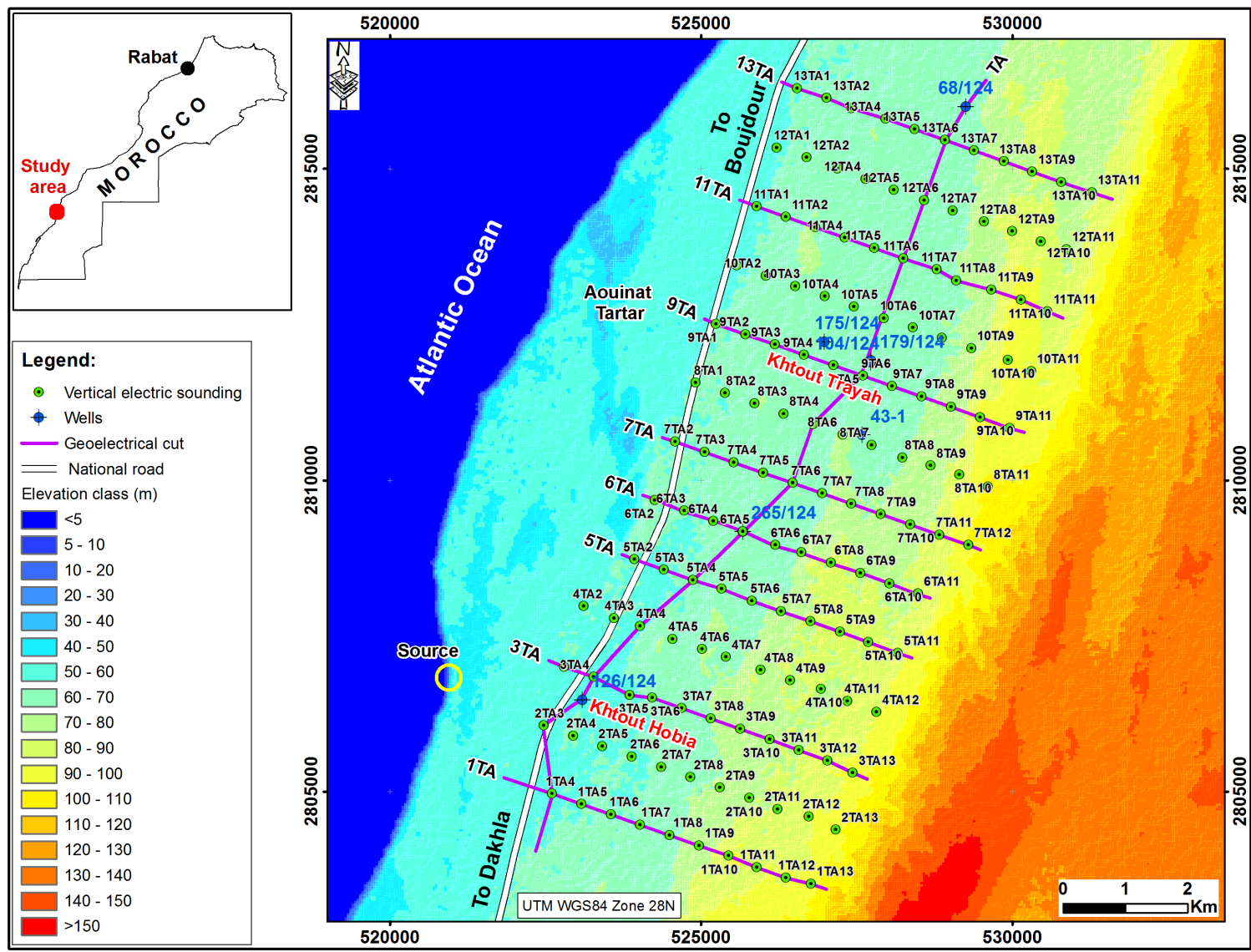

Figure 10. Location plan of the geophysical work carried out. 


\section{NOTE:}

Following the qualitative interpretation of the electric soundings represented by the maps of apparent resistivity's in $A B=200,300$ and $400 \mathrm{~m}$ as well as the preliminary correlations between the different electric soundings, the selected WSW-ENE oriented geoelectric sections are characteristic of the other sections except between sections 5TA and 7TA where it was possible to add the section 6TA passing through hole 265/124 (sec) to better individualize the uplift of the geoelectric levels. This rise separates the collapsed zones located in the South in the vicinity of Khtout Hobia (Well 126/124) and in the North in the vicinity of Khtout Trayh (Well 104/124).

\section{Results and Discussion}

\subsection{Review of Electrical Soundings}

The preliminary interpretation of the electrical soundings is made as the electrical soundings are acquired in order to ensure the correct unwinding of the device and to have a better quality of the measurements. At this stage, it was possible to implement a reconnaissance borehole with a total depth of $67 \mathrm{~m}$ at the plumb of the 6 TA5 electric borehole $(X=525,673, Y=2,809,176, Z=439 \mathrm{~m})$.

The sections of interesting boreholes, both hydraulic and petroleum, were used to identify the geological geological layers of the geoelectric layers highlighted by the diagrams of the electrical boreholes. To this end, it was possible to carry out some electrical boreholes located in the vicinity of boreholes 126/124 (132/124) of Khtout Hobia, 104/124 (179/124) of Khtout Trayh, 265/124, 68/124 and the oil well 43-1.

The interpretation of the diagrams of the all electrical boreholes, carried out with a line length less than or equal to $2000 \mathrm{~m}$, revealed the presence of an alternation of resistant and conductive layers R0, C0 (A0), R (Bc0, Dt0), Dt1, Dt2 directly supporting the conductive deposit noted $\mathrm{C} 1$. This alternation represents the sandy-sandstone formations in which are interspersed clays, conglomeratic levels and limestone banks of Quaternary, Neogene and Eocene age in its highest part. As for conductor $\mathrm{C} 1$, surmounted by this alternation, it corresponds to the clay and silty formations with the presence of flint belonging to the median Eocene starting point. This conductor $\mathrm{C} 1$, well-marked on the diagram, is well developed and reaches a thickness of $250 \mathrm{~m}$ in line with the 20TJ23 standard borehole diagram plumbing oil drilling 43-1 (Figure 11) with a line length $\mathrm{AB}=$ $10,000 \mathrm{~m}$. This conductor surmounts the R2 $+\mathrm{R} 3$ resistant assembly responsible for the final ascent of the curve whose roof reaches a depth of $910 \mathrm{~m}$ coinciding, in its highest part with the carbonate formations of the Eocene base and the silty one with the presence of Paleocene flint. In its basal part, it is attributed to sandy-sandstone formations with upper Cretaceous clay inter-leavings and dolomitic levels and sandy-sandstone formations with lower Cretaceous conglomeratic levels interleaved (Figure 11).

The interpretation of the electric holes made it possible to establish 09 geoelectric sections and 03 interpretive maps (map of the families of the electric 


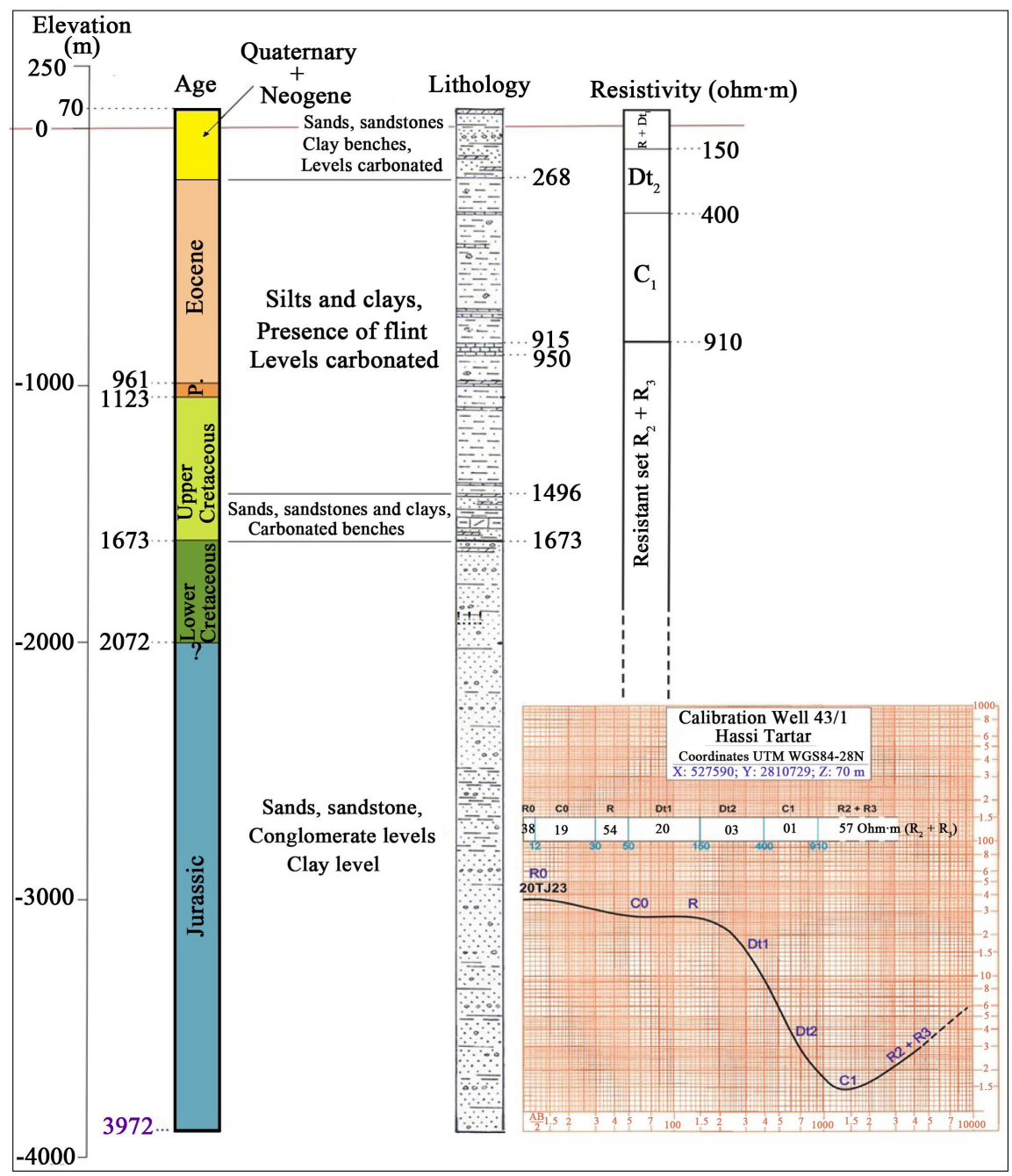

Figure 11. Standard borehole No. 20TJ23 drilled directly into oil well No. 43/1 for the calibration of results.

holes, map of the isohypses of the roof of the intermediate Dt1 and the synthesis map reflecting the main results obtained).

Due to the length of line $A B$ less than or equal to $2000 \mathrm{~m}$ adopted, it was possible to follow only the roofs of levels Dt1, Dt2 and C1 representing the impermeable floor of the sandy-gravel aquifer of the Moghreb-Pleistocene.

For the following, we will only be interested in the covering of the conductor $\mathrm{C} 1$ formed by the alternation of resistant and conductive layers where the resistant level $\mathrm{R}$ (sandstone and sandstone), well-marked on the diagrams of the electric boreholes, is of interest since it is admitted aquifer in the area of the Khtout Hobia and Khtout Trayh wells.

The correlation between the different electrical soundings made it possible to differentiate between two families of electrical soundings A and B (Figure 12), each characterized by a well-defined electrical response. The difference between these two families lies in the geoelectric behaviour of the resistant level R and its sandy-sandstone covering. The eastern part of the study area is dominated by 


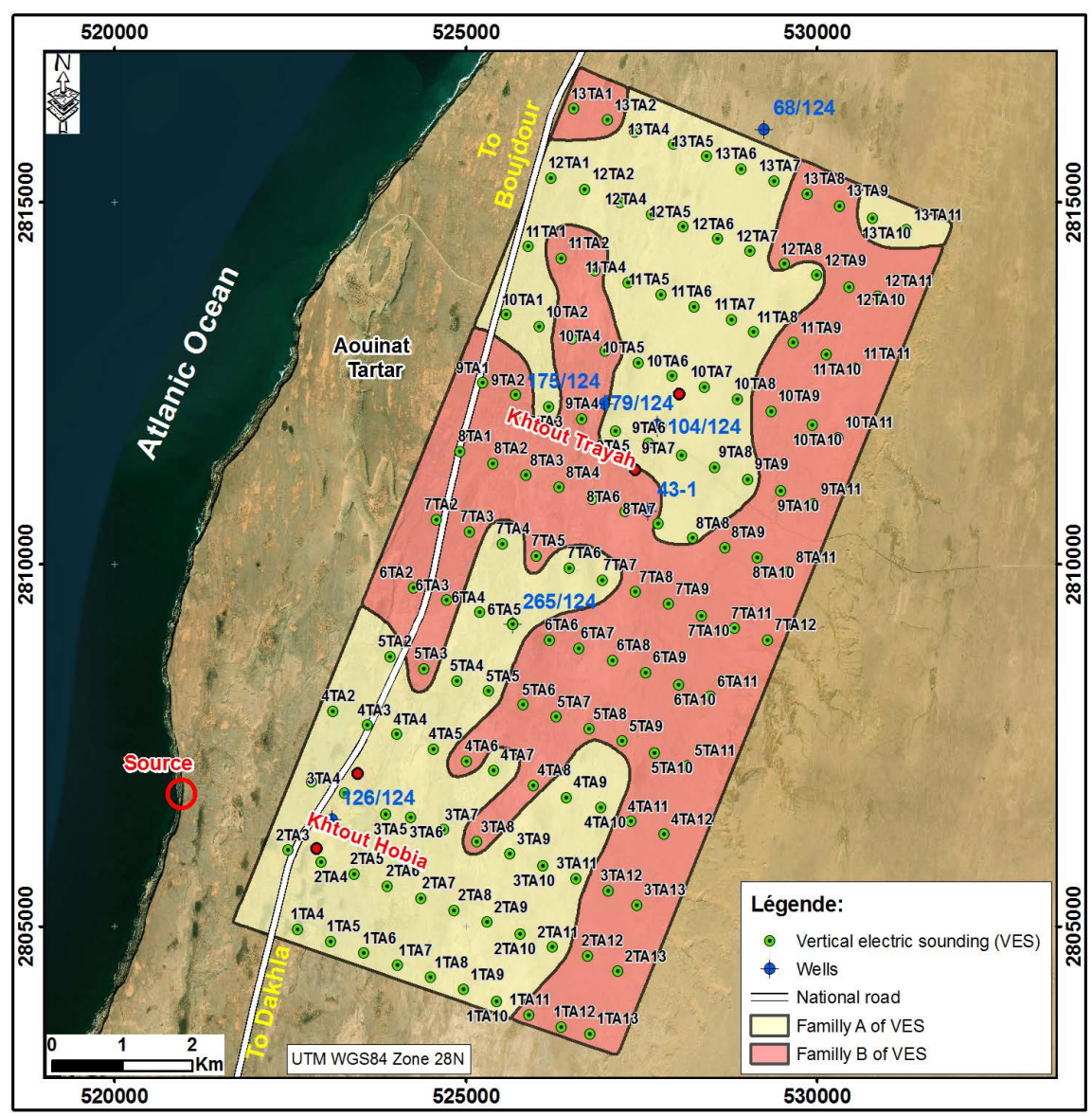

Figure 12. Map of families A and B of vertical electric boreholes.

the presence of the B family of electrical soundings, while the median part of the study area is dominated by the presence of the A family of electrical soundings.

Family A of the electrical soundings is characterized by the diagrams of the 9TA6 (Khtout Trayh 104/124 and 179/124), 13TA6 (68/124), 3TA4 (126/124 132/124), 6TA5 (265/124 reconnaissance drilling) and 3TA6 electrical soundings. This one $\mathrm{B}$ is characterized by the diagrams of the electrical soundings (5TA7 and 7TA3).

The diagrams of the electrical boreholes characterizing these two families A and $\mathrm{B}$ are illustrated in the following figures.

\subsubsection{Family A of Electrical Soundings}

\section{1) Electrical soundings 9TA6, 13 TA6 (Figure 13) and 3TA4 (Figure 14)}

The 9TA6 electric borehole (Figure 13) is located approximately $300 \mathrm{~m}$ from the SSW of wells 104/124 and 179/124 at Khtout Trayh. Unfortunately, the lithological sections of the interesting wells and boreholes in this sector of Khtout Trayh are non-existent, with the exception of the section of well 104/124, which remains provisional and should be used with caution. Its lithological section, communicated by the Sakia El Hamra and Oued Eddahab Hydraulic Basin Agency, is as follows: 


$\begin{array}{cc}0-6 \mathrm{~m}: & \text { Lumachellic limestone slab with siliceous sandstone; } \\ 6-20 \mathrm{~m}: & \text { Coarse sand; } \\ 20-31 \mathrm{~m}: & \text { Yellowish marls; } \\ 31-42 \mathrm{~m}: & \text { Greyish sandy clays; } \\ 42-46 \mathrm{~m}: & \text { Blackish sandy clays (Fine). }\end{array}$

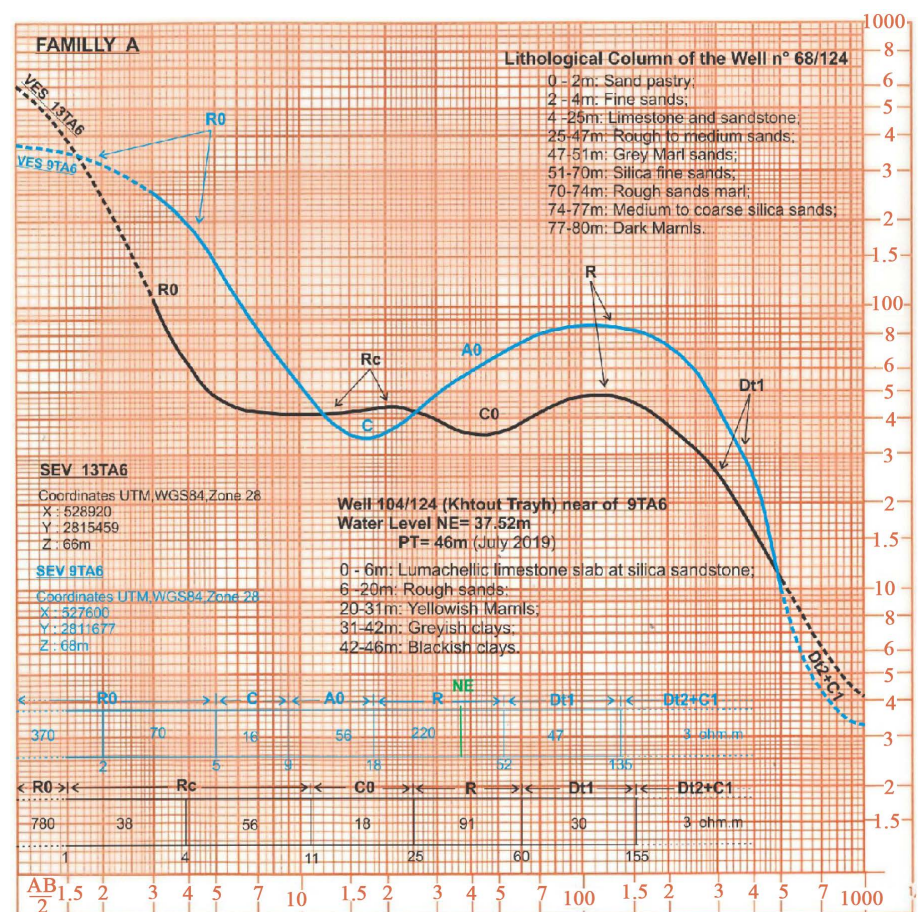

Figure 13. Diagrams of electrical boreholes 9TA6 and 13TA6.

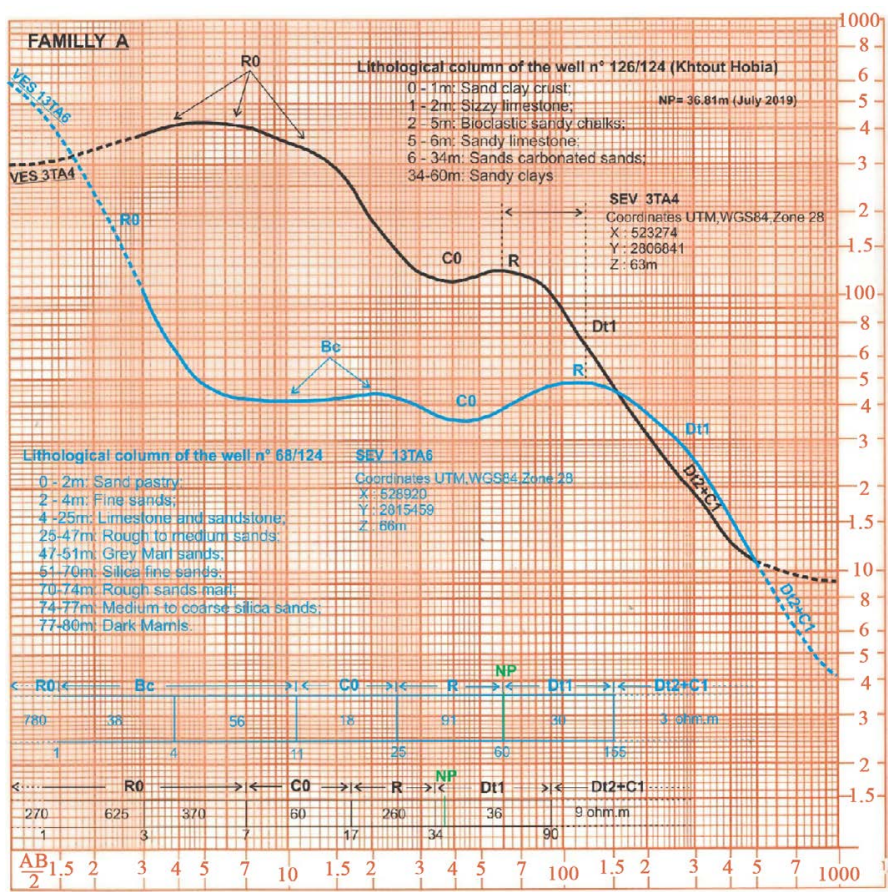

Figure 14. Diagrams of the standard electrical boreholes 3TA4 and 13TA6. 
Examination of the diagram of the electric borehole shows from top to bottom the following layer sequences:

- A surface resistant assembly R0 with a thickness of about $5 \mathrm{~m}$ which would correspond to the lumachellic limestone slab with siliceous sandstones at the base;

- A conductive level C (16 ohm $\cdot \mathrm{m}, 5 \mathrm{~m})$ which could correspond to Holocene sandy marls of the Quaternary roof;

- Above, the intermediate level A0 (56 ohm.m, $9 \mathrm{~m}$ ) which could represent silts, coarse sands and microconglomerates belonging to the Holocene base;

- A resistant level $\mathrm{R}$ well marked on the diagram with a resistivity of 220 $\mathrm{ohm} \cdot \mathrm{m}$ and a thickness of $34 \mathrm{~m}$ which could correspond to whitish to yellowish sandy-gravelly formations and lumachelles of Moghrebian-Pleistocene age. This resistant $\mathrm{R}$ constituted the well-developed aquifer in these sandy-sandstone formations at the Khtout Hobia and Khtout Trayh wells (Tartar Region). The piezometric level, measured in July 2019 (ABHSHOD) at well $104 / 124$, is $40.83 \mathrm{~m}$ with a salinity of $0.46 \mathrm{~g} / \mathrm{l}$. The above-mentioned wells interesting this sector of Khtout Hobia did not completely cross the resistant $\mathrm{R}$ and remained at depths between 41 and $46 \mathrm{~m}$ knowing that the roof of the resistant $\mathrm{R}$ is located at a depth of $52 \mathrm{~m}$;

- An intermediate level Dt1 with a roof not reached by wells with a resistivity of $47 \mathrm{ohm} \cdot \mathrm{m}$ and a thickness of $83 \mathrm{~m}$. In this case, it could correspond to sandy clays on the Miocene roof where the content of sandy passes within this intermediate level has an influence on its resistivity value. The resistivity value of $47 \mathrm{ohm} \cdot \mathrm{m}$ indicates a high content of sandy past within this intermediate Dt1. This level could form the impermeable floor of the slick enclosed within the resistant $\mathrm{R}$ overlying;

- The ensemble surmounts levels Dt2 and C1 whose depth here reaches $135 \mathrm{~m}$ which would represent the carbonate and conglomerate levels of the Neogene base and the clay and silty formations with the presence of Eocene flint.

Electric borehole 13TA6 (Figure 13) is drilled about $700 \mathrm{~m} \mathrm{SSW}$ from borehole 68/124 and 3TA4 (Figure 14) is drilled about $500 \mathrm{~m}$ NNE from borehole 126/124 (Khtout Hobia 132/124 well).

Their lithological sections, communicated by the Sakia El Hamra and Oued Eddahab Hydraulic Basin Agency, are as follows:

\begin{tabular}{cccc}
\hline & 126/124 (Khtout Hobia) & \multicolumn{2}{c}{ 68/124 (North of Khtout Trayh) } \\
\hline $0-1 \mathrm{~m}:$ & Limestone crust; & $0-2 \mathrm{~m}:$ & Limestone encrustation; \\
$1-2 \mathrm{~m}:$ & Sandstone limestones; & $2-4 \mathrm{~m}:$ & Fine sands; \\
$2-5 \mathrm{~m}:$ & Bioclastic sandy chalks; & $4-25 \mathrm{~m}:$ & Calcareous sandstone; \\
$5-6 \mathrm{~m}:$ & Sandy limestones; & $25-47 \mathrm{~m}:$ & Coarse to medium sands; \\
$6-34 \mathrm{~m}:$ & Fine to medium carbonate sands; & $47-51 \mathrm{~m}:$ & Sandy gray marls; \\
$34-60 \mathrm{~m}:$ & Sandy clays (fine). & $51-70 \mathrm{~m}:$ & Fine silica sands; \\
& & $70-74 \mathrm{~m}:$ & Coarse marly sands; \\
& $74-77 \mathrm{~m}:$ & Medium to coarse siliceous sands; \\
& & $77-80 \mathrm{~m}:$ & Dark marls (end).
\end{tabular}


Examination of the diagram of the 13TA6 electrical sounding (Figure 13) shows the presence, in its lower part from the resistor $\mathrm{R}$, of the same succession of resistive and conductive layers $\mathrm{R}, \mathrm{Dt} 1, \mathrm{Dt} 2$ and $\mathrm{C} 1$ as that of the previous 9TA6 diagram (Figure 13). However, in particular, there is a lateral change of facies within the overlap of the resistant level $R$, especially the layer above it where the intermediate level Ao highlighted by the previous diagram has manifested itself electrically as a conductor and is none other than the $\mathrm{C} 0$ conductor with a resistivity of $18 \mathrm{ohm} \cdot \mathrm{m}$. The presence of marl past and fine sands instead of coarse ones at the Holocene base could contribute to a decrease in resistivity from $55 \mathrm{ohm} \cdot \mathrm{m}$ (level A0 -SEV 9TA6, Figure 13) to $18 \mathrm{ohm} \cdot \mathrm{m}$ (level C0-SEV 13TA6, Figure 13) in this case.

In the case of the 3TA4 electric borehole diagram (Figure 14) adjacent to Khtout Hobia wells, the conductor $\mathrm{C} 0$ overlying the resistance level $\mathrm{R}$ has a resistivity value of $55 \mathrm{ohm} \cdot \mathrm{m}$ close to that obtained from the intermediate level A0 in way of the 9TA6 electric borehole diagram (Figure 14).

Comparing the three diagrams of the electrical boreholes mentioned above, especially at the resistant level $\mathrm{R}$ which attracts attention, we observe a remarkable evolution of the resistivity which decreases considerably from South to North. It goes from 262 (SEV 3TA4) to 91 (SEV 13TA6) passing through the value of $221 \mathrm{ohm} \cdot \mathrm{m}$ obtained at the right of the 9TA6 electric borehole.

This decrease in the resistivity of the resistant $\mathrm{R}$ from south to north could be related either to one or to the combined effect of the following factors:

- The change in the facies of resistant $\mathrm{R}$ from a karstified sandstone, lumachelles and carbonate sands facies in the South to sandy facies with marly sands;

- Increasingly high grade from south to north;

- The plunging of the roof and wall of the resistance fighter with an increasingly important development of its roofing. This dive is illustrated in Figure 14.

\section{2) Electrical sounding 6TA5 (Figure 15)}

Following the preliminary interpretation of the electrical holes made just at the end of the acquisition of the field measurements, it was possible to choose the reconnaissance drill site 265/124 directly above the 6 TA5 electrical hole, belonging to family A of the electrical holes, where its diagram (Figure 15) shows the same sequence of electrical layers as the 9TA6 electrical hole diagram (Figure 13). This electrical borehole is located in a high zone where the roof and wall of the resistant $\mathrm{R}$, admitted aquifer, are located respectively 15 and $37 \mathrm{~m}$ deep. Its true resistivity obtained is $112 \mathrm{ohm} \cdot \mathrm{m}$ with a thickness of $22 \mathrm{~m}$. This borehole is dry.

\section{3) Electrical sounding 3TA6 (Figure 16)}

This electrical borehole is located approximately $2 \mathrm{~km} \mathrm{SE}$ of the 126/124 Khtout Hobia well. Its diagram (Figure 16) is part of family A of electrical boreholes with the same succession of resistant and conductive layers as the above-mentioned electrical borehole diagrams (9TA6 and 6TA5). 


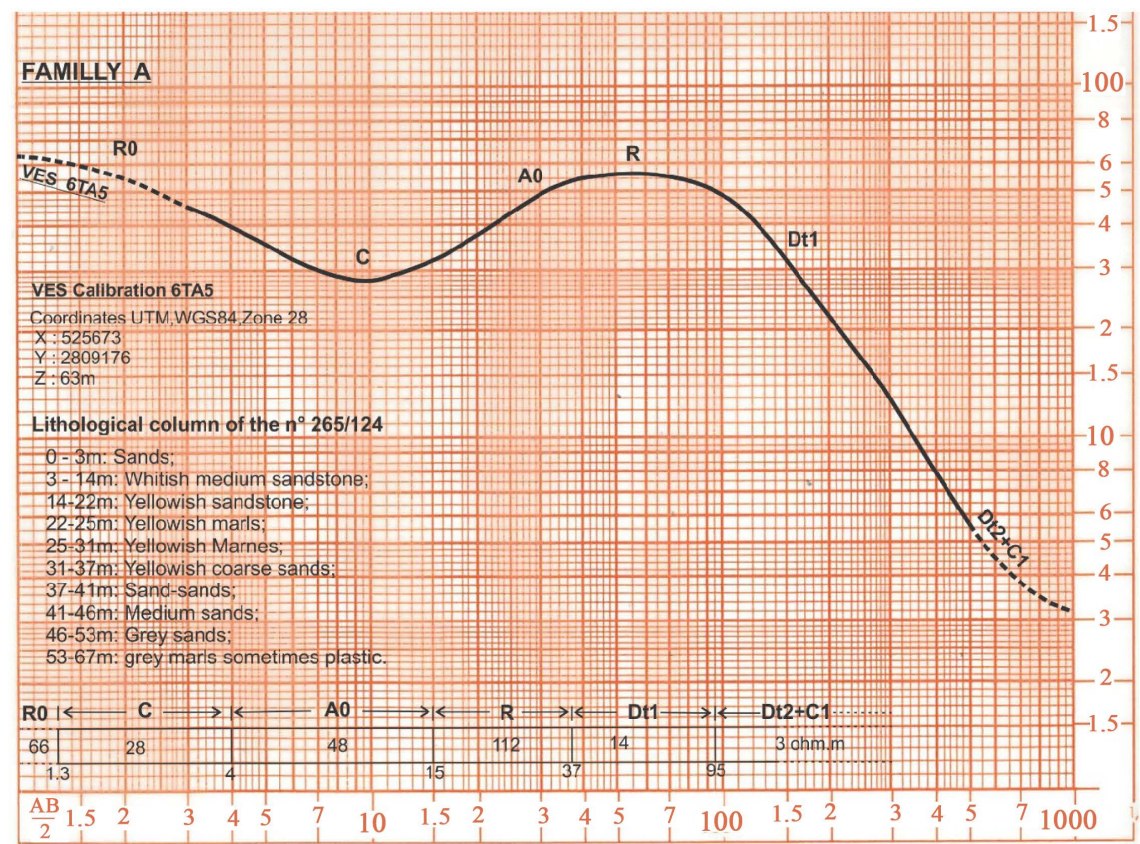

Figure 15. Diagram of the 6TA5 standard sounding.

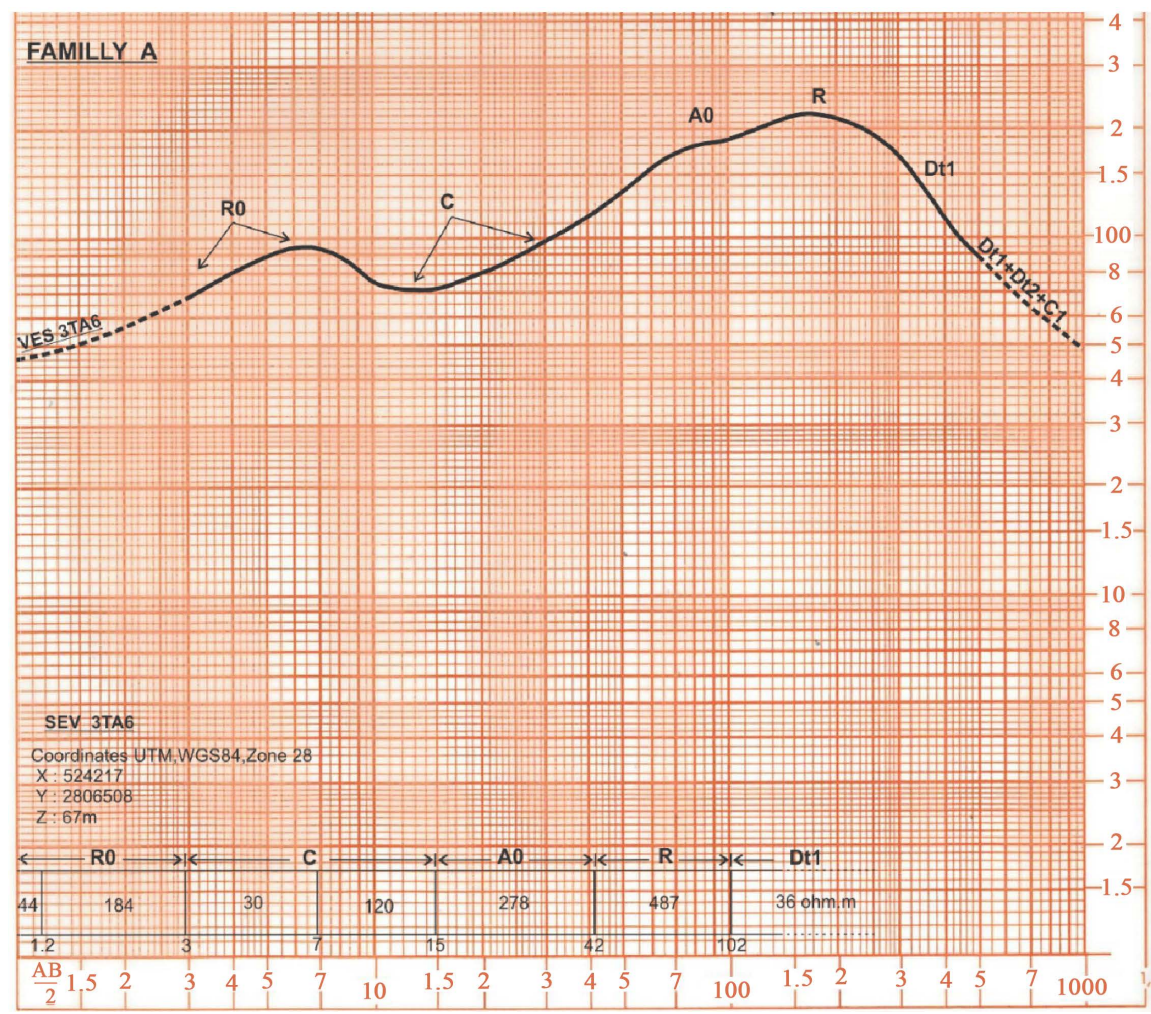

Figure 16. Bilogarithmic diagram of electric borehole number 3TA6.

In this case of the diagram, we are witnessing, in particular, a deepening of the roof and wall of the resistant level $\mathrm{R}$ which reach depths of 32 and $84 \mathrm{~m}$ respectively with a thickening of the resistant $\mathrm{R}$ and its covering where the thickness of resistant $R$ reaches $52 \mathrm{~m}$ instead of 34 to $35 \mathrm{~m}$ at the level of the electrical 
soundings 9TA6 (Khtout Trayh) and 13TA6. As for its resistivity reached, in this case, of $278 \mathrm{ohm} \cdot \mathrm{m}$, it remains comparable to that obtained from the 3TA4 electric borehole of $262 \mathrm{ohm} \cdot \mathrm{m}$. The presence of karstified sandstone and lumachelle formations and carbonate sands within the resistant $\mathrm{R}$ are at the origin of the relatively high resistivity. This type of diagram is located in highly collapsed areas.

These subsidences, filled with Miocene lumachellique sandstone formations, seemed to favour the important development of the resistant level $\mathrm{R}$ and its covering. The resistant $\mathrm{R}$ would correspond, in its highest part, to the sandstones and lumachelles of the Moghrebian-Pleistocene (Marine Pliocene) age and to the lumachellique sandstones and limestones of the Miocene age (Ugranat Formation) of the Neogene roof. In contrast, outside the heavily subsided areas, at the level of the area characterized by the presence of family A of electric boreholes, as in the case of the diagrams of electric boreholes 13TA6, 9TA6 (Figure 13) and 3TA4 (Figure 14) where the sandstone formations of the Moghreb-Pleistocene surmount the sandy marls of the Miocene roof (intermediate level Dt1).

\subsubsection{Family B of Electrical Soundings (Figure 17)}

The diagrams of the 5TA7 and 7TA3 electrical boreholes (Figure 17) were chosen to highlight the lateral change in the facies of the top part of the resistant level $\mathrm{R}$ of family $\mathrm{A}$ of the electrical boreholes. This resistor $\mathrm{R}$ manifested itself electrically, in this case of diagram, sometimes in a downward bilayer Bc0 (electric borehole 5TA7) and sometimes in an intermediate level descending Dt0 (electric borehole 7TA3).

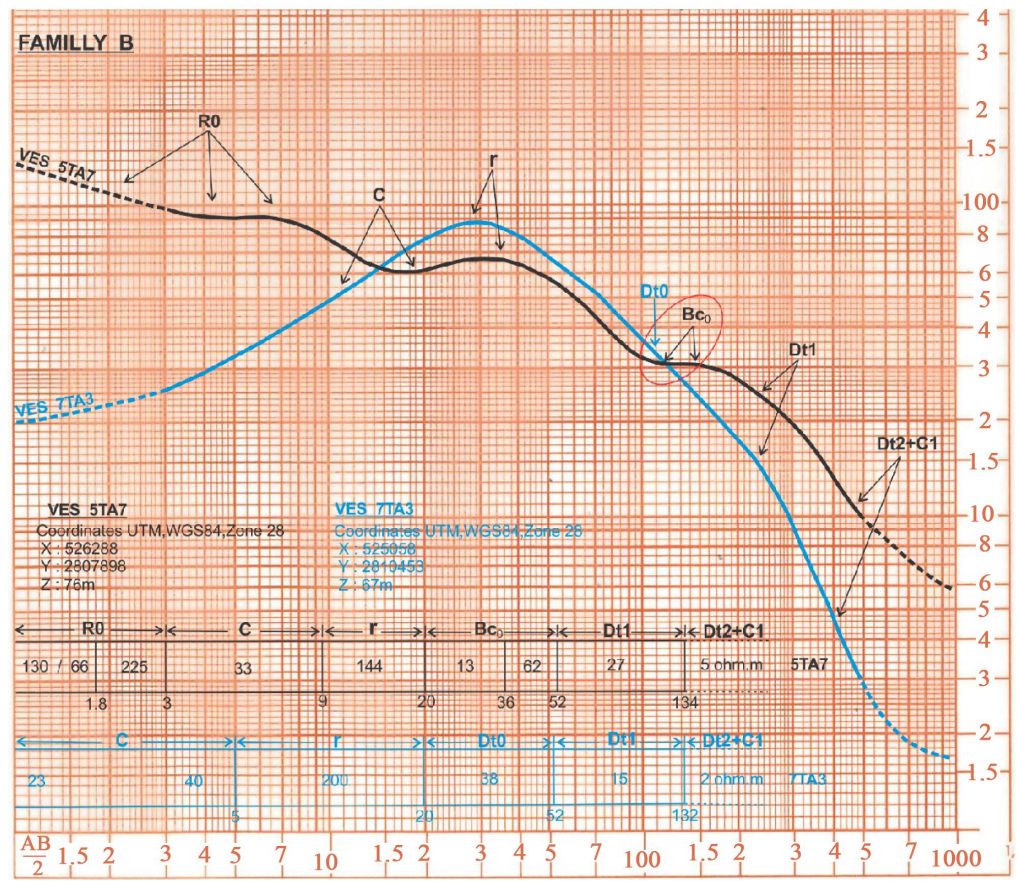

Figure 17. Diagrams of the 5TA7 and 7TA3 electrical boreholes. 
The sandy formations of the Moghreb-Pleistocene represented by the Resistance $\mathrm{R}$ would seem to have suffered, at first, a significant continental erosion where the top part of the sandy sand formations was stripped and then covered by the sandy marls constituting the conductor of the bilayer $\mathrm{Bc} 0$ during a marine advance (Regression). This conductor has a resistivity of $13 \mathrm{ohm} \cdot \mathrm{m}$ and a thickness of $18 \mathrm{~m}$, while the resistance of the base of the bilayer $\mathrm{Bc} 0$ is $62 \mathrm{ohm} \cdot \mathrm{m}$ with a thickness of $18 \mathrm{~m}$.

\subsection{Analysis of the Apparent Resistivity Maps in $A B=200,300$ and $400 \mathrm{~m}$ (Figures 18-20)}

They are based on the gross apparent resistivity values $(\rho a)$ recorded at each electrical borehole measuring station for line lengths $A B=200 \mathrm{~m}, \mathrm{AB}=300$ and $\mathrm{AB}=400 \mathrm{~m}$. They have a qualitative aspect taking into account the factors that influence these measurements such as the variation in altitude between electrical boreholes, the resistivities of surface soils and the lateral variations in facies.

The 03 maps (Figures 18-20) reflect the electrical behaviour of the resistant level $\mathrm{R}$ and, in places, that of the underlying intermediate level Dt1, whose roof would sometimes correspond to sandy-gravel formations, especially in subsided areas, and sometimes to sandy marls outside these subsidised areas.

Simultaneous analysis of these three maps shows, overall, the presence of the following three apparent resistivity ranges:

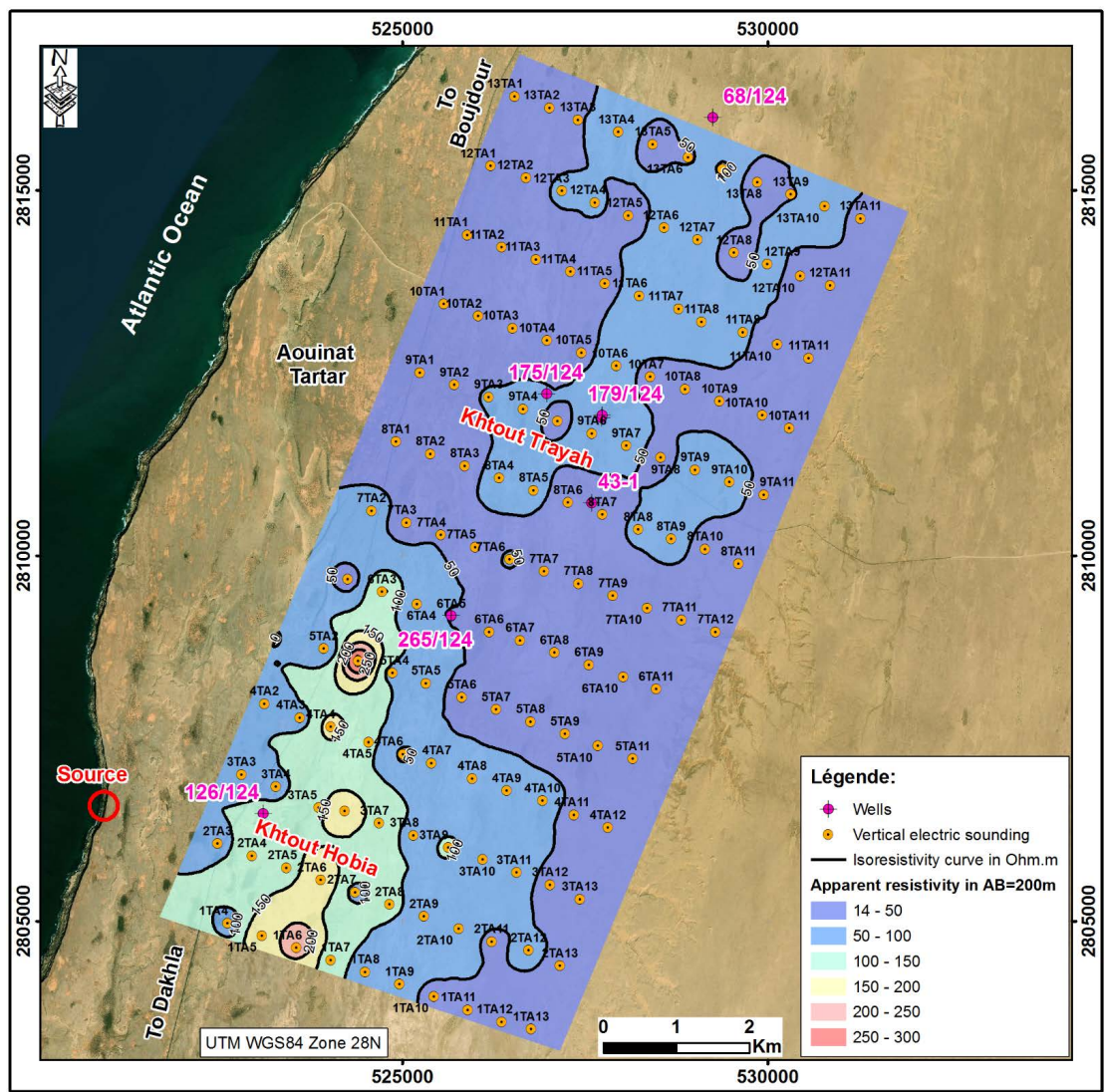

Figure 18. Iso-resistivity map of the apparent resistivity in $\mathrm{AB}=200 \mathrm{~m}$. 


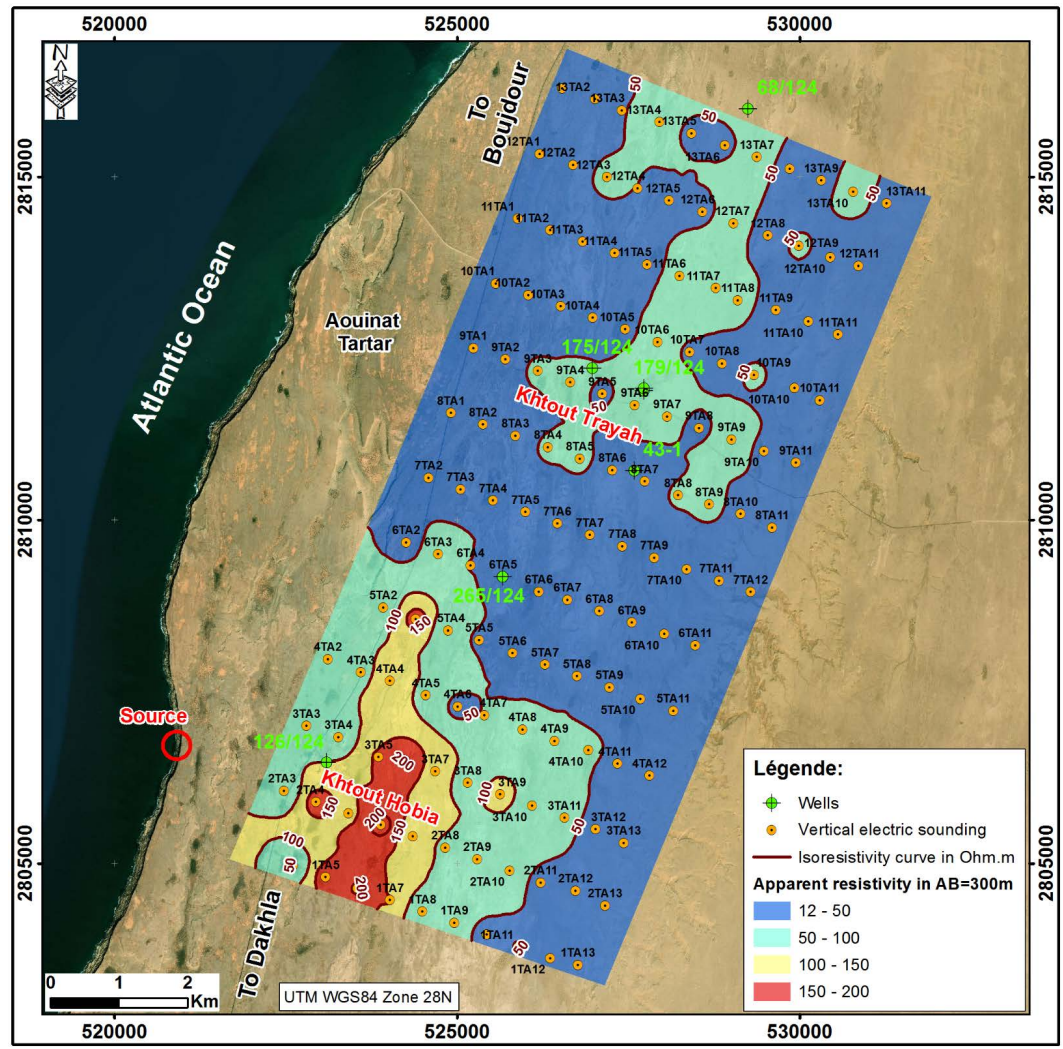

Figure 19. Iso-resistivity map of the apparent resistivity in $A B=300 \mathrm{~m}$.

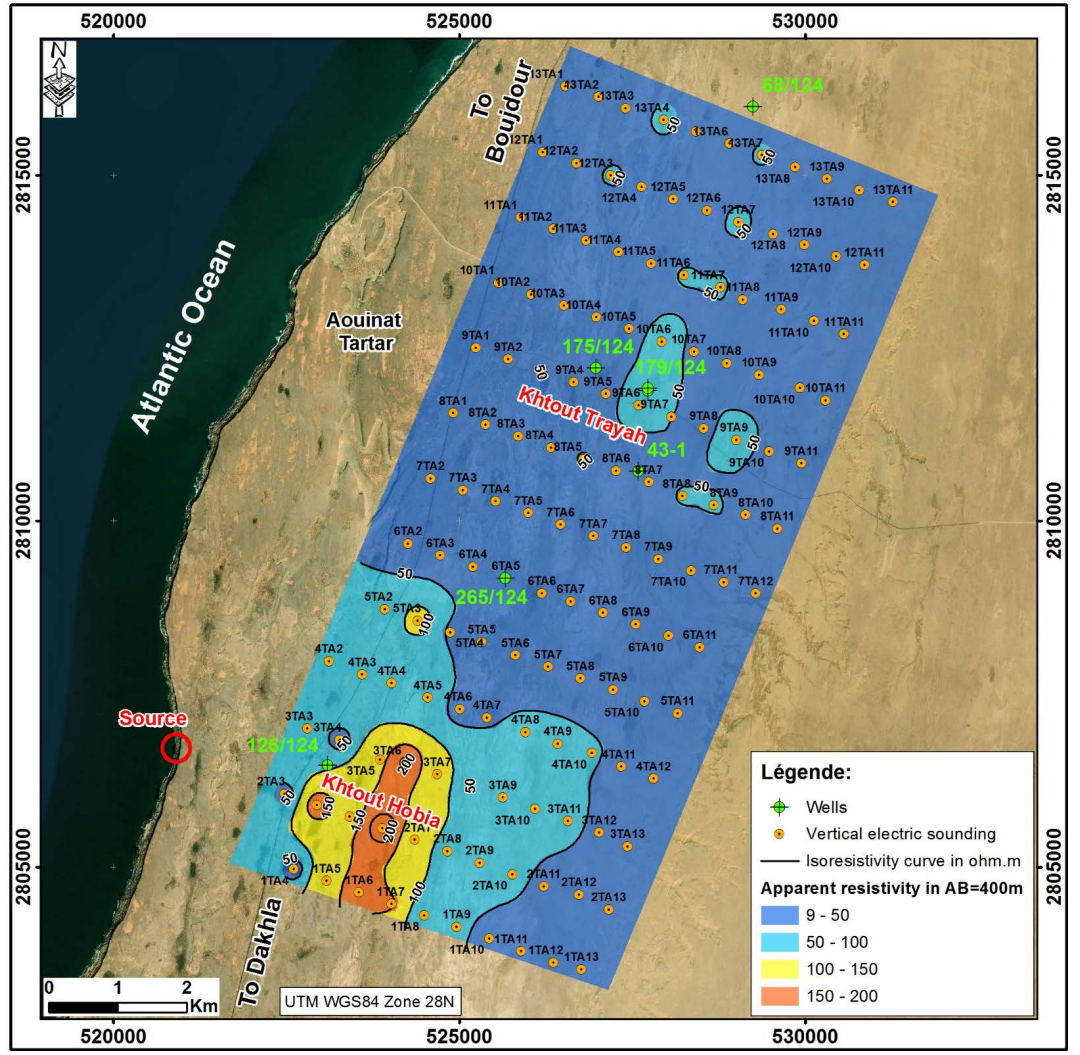

Figure 20. Iso-resistivity map of the apparent resistivity in $A B=400 \mathrm{~m}$. 
- A conductive beach limited by the $50 \mathrm{ohm} \cdot \mathrm{m}$ curve of vast extent of low gradient occupying the median and northern zones of a resistivity of less than 50 $\mathrm{ohm} \cdot \mathrm{m}$ reflecting the presence of sandy marl on the roof of the intermediate level Dt1. This conductive range becomes more important on the apparent resistivity map in $\mathrm{AB}=400 \mathrm{~m}$;

- A moderately resistant beach with a resistivity of between 50 and $100 \mathrm{ohm} \cdot \mathrm{m}$, reflecting the presence of sandy-sandish to sandy formations within the resistant level R. This beach characterizes the area of the 104/124 well at Khtout Trayh. This range remains comparable to the level of the apparent resistivity maps in $B=200$ and $A B=300 \mathrm{~m}$ and is considerably attenuated in the vicinity of Khtout Trayh on the apparent resistivity map in $\mathrm{AB}=400 \mathrm{~m}$, reflecting the presence of sandy marls represented by the intermediate level Dt1 at this line length $\mathrm{AB}=400 \mathrm{~m}$;

- A relatively resistant range of strong gradients well marked on the three resistivity maps in $\mathrm{AB}=200, \mathrm{AB}=300$ and $\mathrm{AB}=400 \mathrm{~m}$ with a resistivity well above $150 \mathrm{ohm} \cdot \mathrm{m}$ located in the southwestern part of the study area near the Khtout Hobia well. This beach reflects the subsidence of the roof and wall of the resistant $\mathrm{R}$, which consists essentially of karstified and lumachellique sandstone formations.

\subsection{Analysis of Geoelectric Sections}

The electric boreholes were carried out along the parallel profiles of direction substantially NE-SW more or less parallel to the Atlantic Ocean.

A total of eight (08) geo-electric sections-oriented NNW-SSE and one (01) SW-NE oriented section cutting the eight sections were established from the data of the quantitative interpretation of the electrical soundings (Figure 10 cited above). The correlations made have a physical meaning based on the values of the true resistivities obtained at each electrical borehole.

These geoelectric sections (Figure 21) were used to develop the interpretive map of the Dt1 intermediate roof isohypses (Figure 22) and the synthetic map (Figure 23).

All sections are represented at the same horizontal scale of 1/50,000 and vertical scale of 1/2000 except the one crossing the 08 sections where the scale chosen horizontally of $1 / 200,000$ and vertically of $1 / 2000$. This is to better identify the thin layers belonging to the coverage of the intermediate level Dt1.

On all established geoelectric sections, it was possible to follow, in particular, the evolution of the roofs and walls of the geoelectric levels R0, C0 (A0), R (Dt0, $\mathrm{Bc} 0)$, Dt1, Dt2 and C1.

On most sections, there are many electrical discontinuities affecting the Plio-quaternary and sometimes Neogene formations. Indeed, the electrical discontinuities observed in the sandy-sandstone and lumachelle formations of the Moghreb-Pleistocene could correspond to lateral changes in the facies of the roof of the resistance $\mathrm{R}$ representing a limit of the erosion surface within the 


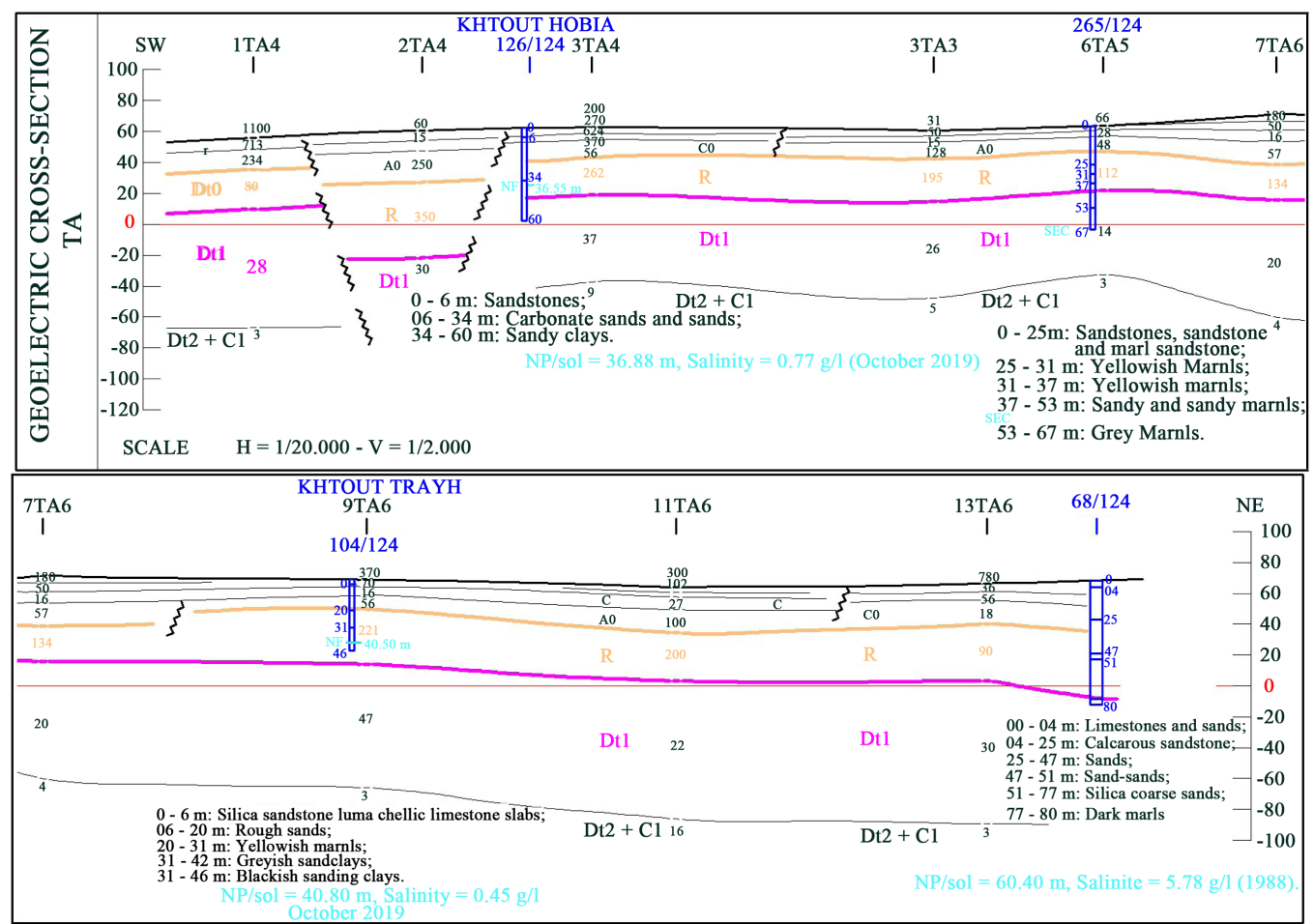

Figure 21. Geo-electric section TA.

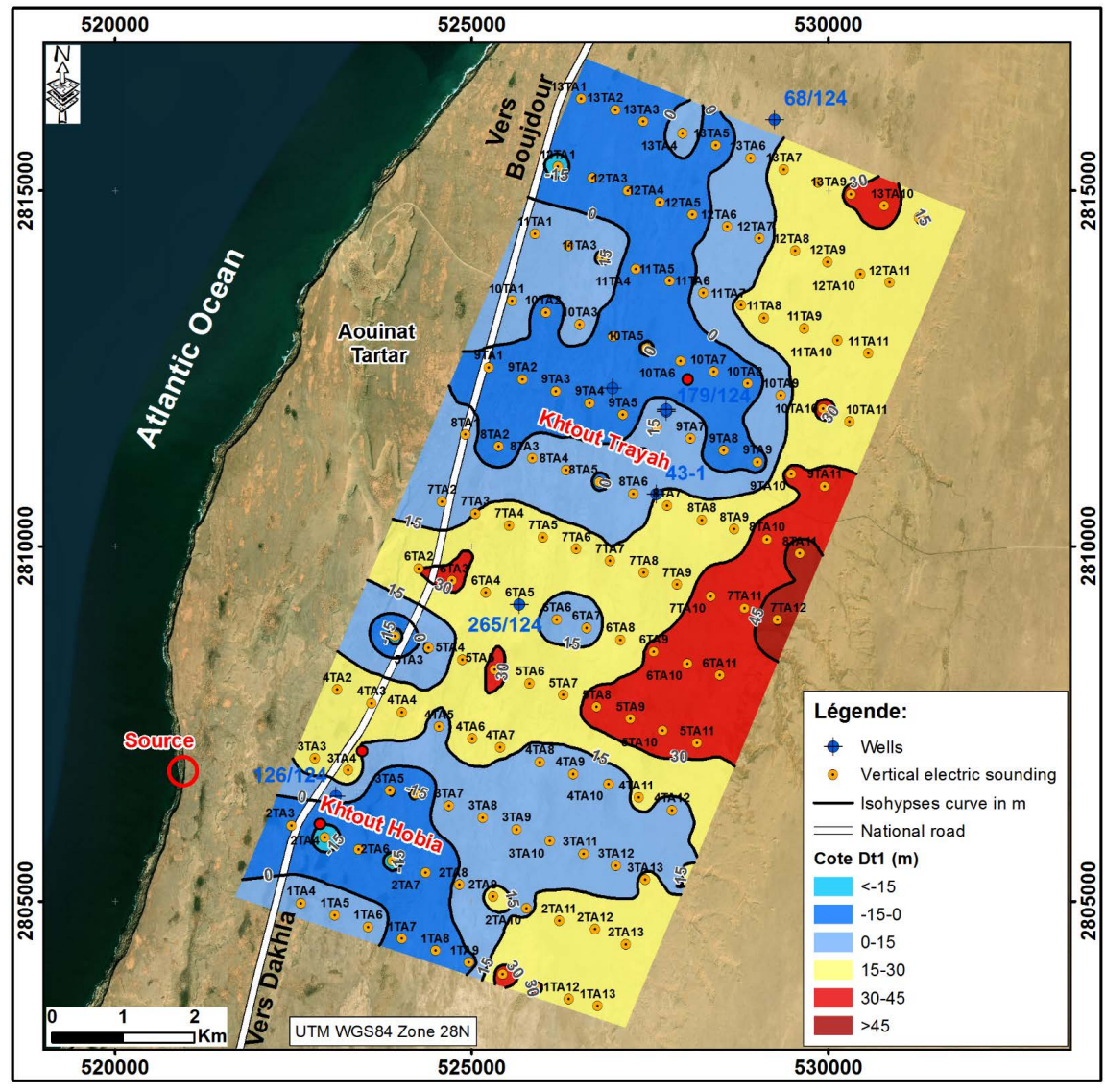

Figure 22. Map of roof isohypses of the intermediate electrical level Dt1 rating. 


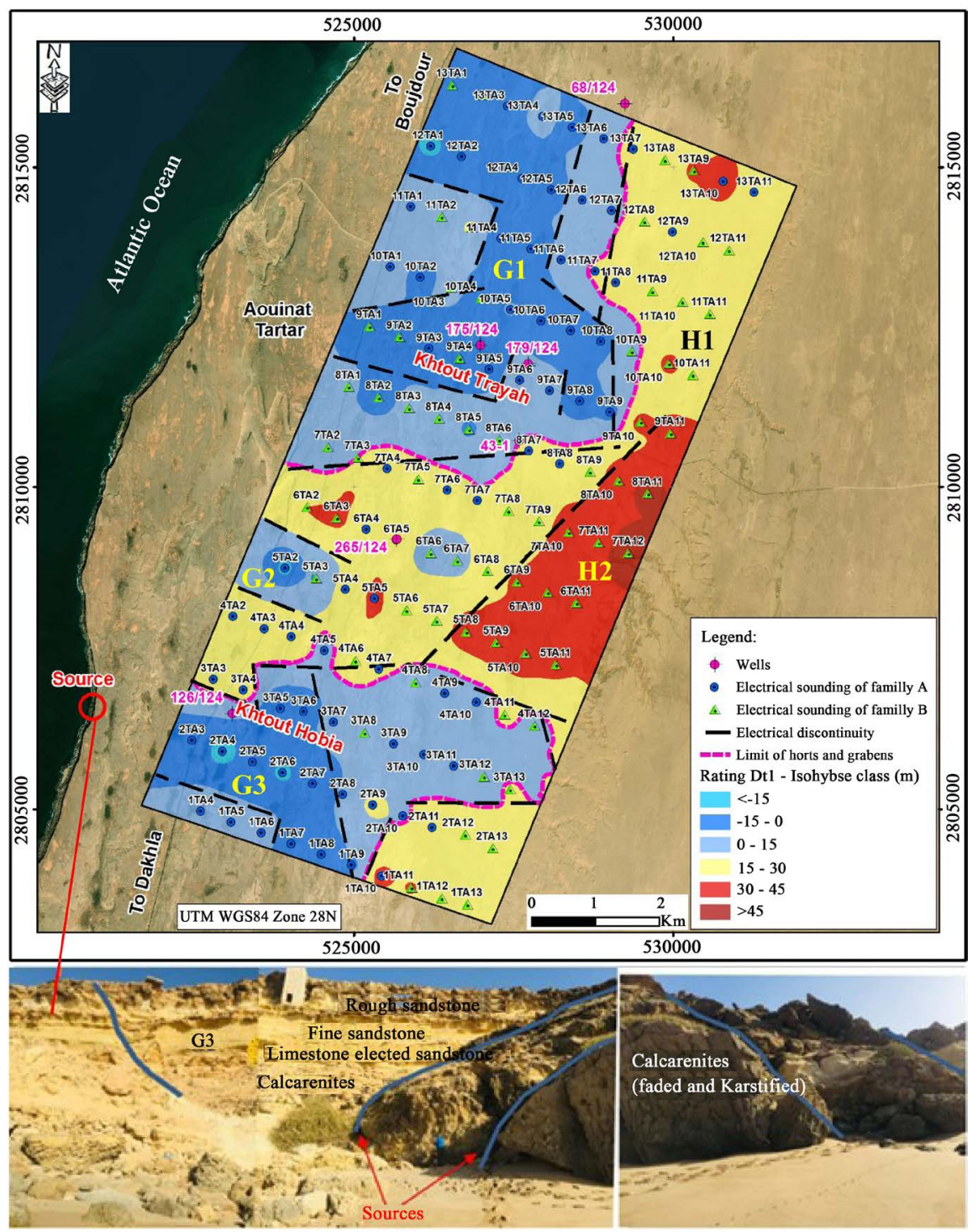

Figure 23. Synthesis map of study results.

resistance R. Those observed in the plio-quaternary and Neogene formations would correspond either to syn-sedimentary faults composed of two main families N50 and N140 which structured the area into horsts and grabens. The latter are well marked on sections 1TA, 3TA, 9TA and 11TA where we are witnessing, in particular, the significant development of the resistant level $\mathrm{R}$ which reaches an average thickness of $50 \mathrm{~m}$ with a very variable resistivity reaching values higher than $200 \mathrm{ohm} \cdot \mathrm{m}$ in the SE in the vicinity of Khtout Hobia (Resistant R to lumachellique sandstone facies) and resistivity values below $100 \mathrm{ohm} \cdot \mathrm{m}$ in the NE in the vicinity of Khtout Trayh (Resistant $\mathrm{R}$ to sandy facies). The lowest points are located in way of the electrical boreholes 2TA4, 5TA2 and 12TA1 where the roofs of the resistant and intermediate levels Dt1 reach depths of 34 and $84 \mathrm{~m}$ respectively.

On the 4TA, 5TA, 6TA and 7TA in their median and western parts, and on 
the 11TA, 12TA and 13TA sections, in their eastern part, there are high areas drawn particularly by the roofs of the resistant levels $\mathrm{R}$ and intermediate Dt1 where their roofs do not exceed respectively 20 and $40 \mathrm{~m}$ in depth.

Examination of the TA cross-section shows a general immersion of the roofs of the resistant level R and the intermediate Dt1 of SW towards the NE with the presence of a slight rise of these roofs in way of the electric borehole 6TA5, chosen for the realization of the reconnaissance borehole 265/124 where these roofs reach depths of 15 and $37 \mathrm{~m}$ respectively.

At the SW end of section TA, we note the presence of a collapsed zone centred on the 2TA3 electrical borehole bordered by two electrical discontinuities that would correspond to synedimentary faults where the resistant $\mathrm{R}$, attributed to Moghrebian Pleistocene sandstones and lumachelles and Miocene roof sandstones, is well developed and reaches a thickness of about $50 \mathrm{~m}$ with a resistivity of $350 \mathrm{ohm} \cdot \mathrm{m}$.

\subsection{Analysis of the Map of the Roof Isohypses of the Intermediate Level Dt1 Roof (Figure 22)}

Following the quantitative interpretation of the electrical boreholes, it was possible to map the isohypses giving the appearance of the roof of the intermediate level Dt1 corresponding to the sandy marl marls of the Miocene roof. This map is represented at a scale of $1 / 50,000$ and is drawn with an equidistance of about $15 \mathrm{~m}$.

In general, the examination of this map gives an idea of the behaviour of the roof of the intermediate level Dt1 corresponding to the roof of the Miocene formations (marls with sandy marls. This level Dt1 represents the wall of the resistant level R (Moghrebo-Pleistocene Formations) admitted aquiferous, known at the Khtout Hobia (126/124) and Khtout Trayh (104/124) wells.

The roof elevation of the intermediate level Dt1 varies considerably between $61 \mathrm{~m}$, the highest point in the study area (SEV 7TA12) and $-22 \mathrm{~m}$, the lowest point in the study area (SEV 2TA4).

Analysis of this map shows the following:

- Three collapsed zones marked G1, G2 and G3 limited by the $15 \mathrm{~m}$ isohypse curve. These areas are characterized by the presence of a low to medium gradient of isohypses. The first G1 is centered on the 12TA1 electric borehole $(-19 \mathrm{~m})$, the second is centered on the 5TA2 electric borehole $(-20 \mathrm{~m})$ and the third is centered on the 2TA4 electric borehole $(-22 \mathrm{~m})$.

- Two high zones noted $\mathrm{H} 1$ and $\mathrm{H} 2$ where the first, of vast extent, is located between the isohypsis curves 15 and $30 \mathrm{~m}$, the second, of rather reduced extension, is limited between the isohypsis curves 30 and $60 \mathrm{~m}$. They are characterized by the presence of a low to medium gradient.

The strong gradient of the isohypses, reflecting the sudden change in the rating of the intermediate level Dt1, is observed between the collapsed zones G1, G2 and G3 and those high $\mathrm{H} 1$ and $\mathrm{H} 2$ showing the presence of electrical discon- 
tinuities affecting the coverage of the conductive level $\mathrm{C} 1$ (Eocene formations). These discontinuities, already put in place by the geoelectric sections and the correlation between the various electrical holes, would correspond to synedimentary faults that have compartmentalized the structure into a system of horsts $\mathrm{H} 1$ and $\mathrm{H} 2$ and grabens G1, G2 and G3.

\section{Conclusions}

The interpretation of the electric soundings in $A B \leq 2000 \mathrm{~m}$, the reinterpretation of some VES in $\mathrm{AB}=10,000 \mathrm{~m}$ revealed the presence of two (02) Families A and $B$ of electric soundings separated by electric discontinuities affecting the top of the resistant $\mathrm{R}$. They would correspond to lateral changes of facies at the level of the contact between the Moghrebo-Pleistocene formations and those of the Upper Miocene (erosion surface).

Examination of the TA cross section and the map of the isohypses of the roof of intermediate Dt1 showed the presence of two (02) horsts H1 and H2; and three (03) Grabens G1, G2 and G3 affected by electrical discontinuities that would correspond to syn-sedimentary faults where the horsts separate G1 and G2 forming a tight boundary between the two Hobia Groundwater aquifers (Well 265/124). The map of the isohypses gave an idea of the shape of the roof of the intermediate level (Dt1) representing the impermeable floor of the aquifer-accepted $\mathrm{R}$ resistant.

The main results obtained as mentioned above are illustrated by the synthesis map shown in Figure 23.

At this stage, it could be the presence of two aquifers; one aquifer enclosed by the calcareous sandstones and the lumachellic with a salinity close to $0.8 \mathrm{~g} / \mathrm{l}$ located at the level of Khtout Hobia, another aquifer enclosed by the sands with a salinity close to $0.4 \mathrm{~g} / \mathrm{l}$ located at the level of Khtout Trayh. These two aquifers are located respectively inside the G3 and G1 gravels.

In terms of perspectives, it is suggested the establishment of other water points within the G1, G2 and G3 gravels. Other complementary geophysical studies should also be carried out in the North and South to delineate the two aquifers in order to develop a conceptual model of these aquifers.

\section{Acknowledgements}

The authors thank the Watershed Agency of Saguia El Hamra and Oued Eddahab (ABHSHOD) for providing the necessary data. Thanks also go to AFRICAGEO-SERVICES for making hydro-geophysical equipment and processing software available for this work.

\section{Conflicts of Interest}

The authors declare no conflicts of interest regarding the publication of this paper. 


\section{References}

[1] ABHSHOD (Basin Agency Sakia El Hamra Hydraulics and Oued Ed-Dahab) (2011) Exhaustive Inventory Withdrawals of Groundwater in the Basin Sakia El Hamra and Oued Ed-Dahab. Report 02/2010/ABHSHOD, Mission I, 69 p.

[2] El Mokhtar, M., Chibout, M., Kili, M., EL Mansouri, B., et al. (2018) Evaluation of Saline Intrusion in the Groundwater of Foum El Oued Province of Laayoune, Morocco. Bulletin of the Scientific Institute of Rabat, Section Earth Sciences, 40, 53-69. http://www.israbat.ac.ma/wpcontent/uploads/2018/11/El_Mokhtar_et_al_Final.pdf

[3] Dillon, R.S. and Soujy, G. (1974) Geology of West Africa and Canary and Cape Verde Islands. In: Nairn, A.E.M. and Stehli, F.G., Eds., The Ocean Basins and Margin, Plenum Press, The North Atlantic, New York, 315-390. https://doi.org/10.1007/978-1-4684-3033-2_10

[4] Lehner, P. and De Ruiter, P. (1977) Structural History of the Atlantic Margin of Africa. American Association of Petroleum Geologists Bulletin, 61, 961-981. https://doi.org/10.1306/C1EA43B0-16C9-11D7-8645000102C1865D

[5] Alia Medina, M. (1945) Geological Morphographic Features and the Northern Spanish Sahara Area. Trabalho National Science Institute, No. 4, 260 p.

[6] Alia Medina, M. (1945) Quaternary El espanol en el Sahara. Newsletter of the Sociedad Española de Historia Natural, 43, 149-163.

[7] Lecointre, G. (1952) Research on the marine Neogene and Quaternary of the Atlantic coast of Morocco. Notes and Memoirs Service. Geological Morocco, 3, No. 174.

[8] Choubert, G. and Ambroggi, R. (1953) Preliminary Note on the Presence of Two Sedimentary Cycles in the Pliocene Marine Morocco. Notes and Memoirs Service. Geological Morocco, 7, 5-53.

[9] Lecointre, G. (1963) Note on the Neogene and Quaternary Marine Spanish Sahara (Seguiet el Hamra and Rio de Oro). Notes y Comunicaciones del Instituto Geológico y Minero de Espana, No. 71.

[10] Lecointre, G. (1965) A Hypothesis on the Age of Quaternary Transgression in Mauritania. Notes and Memoirs Service. Geological Morocco, 25, 79-80.

[11] Lecointre, G. (1966) Neogene and Quaternary Tarfaya Coastal Basin. Notes and Memoirs Service. Geological Morocco, No. 175, 255-288.

[12] Martinis, B. and Visintin, V. (1966) Geological Data on the Coastal Sedimentary Basin of Tarfaya (Morocco Southern). In: Reyre, D., Ed., Sedimentary Basins of the African Coast, Part 1 (Atlantic Coast), Association of African Geological Soundings, UNESCO, 13-26.

[13] Ratschiller, L.K. (1970) Lithostratigraphy of the Northern Sahara Spanisch. Memoria Museo Tridentino di Scienze Naurali trento, 18, 9-78.

[14] CGG (1961) Study Geophysical Seismic Reflection Oil in the Sedimentary Basin Laayoune-Dakhla. Report DRH, 60 p.

[15] ISM (Institute of Spanish Mines) (1971) Geological Map of 1/200000e. Geological Institute of Spanish Mines, Madrid.

[16] Astier, J.L. (1971) Geophysical Applications in Hydrogeology. Masson, Paris, 275 p.

[17] Chouteau, T. (2001) Electrical Methods, Course Notes, Ecole Polytechnique, Montreal.

[18] Telford, W.M., Geldart, L.P. and Sherif, R.E. (1990) Applied Geophysics. Cambridge University Press, Cambridge, $770 \mathrm{p}$. 
[19] Loke, M.H. and Barker, R.D. (1996) Rapid Least-Squares Inversion of Apparent Resistivity Pseudosections by a Quasi-Newton Method. Geophysical Prospecting, 44, 131-152. https://doi.org/10.1111/j.1365-2478.1996.tb00142.x

[20] Reynolds, J.M. (2003) An Introduction to Applied and Environmental Geophysics. Wiley, London, UK, 796 p. 